\title{
Structural and evolutionary divergence of eukaryotic protein kinases in Apicomplexa
}

\author{
Eric Talevich ${ }^{1}$, Amar Mirza ${ }^{2}$ and Natarajan Kannan ${ }^{1,2^{*}}$
}

\begin{abstract}
Background: The Apicomplexa constitute an evolutionarily divergent phylum of protozoan pathogens responsible for widespread parasitic diseases such as malaria and toxoplasmosis. Many cellular functions in these medically important organisms are controlled by protein kinases, which have emerged as promising drug targets for parasitic diseases. However, an incomplete understanding of how apicomplexan kinases structurally and mechanistically differ from their host counterparts has hindered drug development efforts to target parasite kinases.

Results: We used the wealth of sequence data recently made available for 15 apicomplexan species to identify the kinome of each species and quantify the evolutionary constraints imposed on each family of apicomplexan kinases. Our analysis revealed lineage-specific adaptations in selected families, namely cyclin-dependent kinase (CDK), calcium-dependent protein kinase (CDPK) and CLK/LAMMER, which have been identified as important in the pathogenesis of these organisms. Bayesian analysis of selective constraints imposed on these families identified the sequence and structural features that most distinguish apicomplexan protein kinases from their homologs in model organisms and other eukaryotes. In particular, in a subfamily of CDKs orthologous to Plasmodium falciparum crk-5, the activation loop contains a novel PTxC motif which is absent from all CDKs outside Apicomplexa. Our analysis also suggests a convergent mode of regulation in a subset of apicomplexan CDPKs and mammalian MAPKs involving a commonly conserved arginine in the $\alpha$ C helix. In all recognized apicomplexan CLKs, we find a set of co-conserved residues involved in substrate recognition and docking that are distinct from metazoan CLKs.

Conclusions: We pinpoint key conserved residues that can be predicted to mediate functional differences from eukaryotic homologs in three identified kinase families. We discuss the structural, functional and evolutionary implications of these lineage-specific variations and propose specific hypotheses for experimental investigation. The apicomplexan-specific kinase features reported in this study can be used in the design of selective kinase inhibitors.
\end{abstract}

\section{Background}

The parasitic protists which comprise the phylum Apicomplexa are responsible for human diseases of global importance, such as malaria (caused by Plasmodium falciparum and other members of the Plasmodium genus), cryptosporidiosis (Cryptosporidium species) and toxoplasmosis (Toxoplasma gondii), as well as the agricultural diseases babesiosis (Babesia bovis in cattle) and coccidiosis (Eimeria tenella in chickens) [1]. In recent years, understanding of the molecular biology and evolution of this phylum has improved dramatically; yet effective treatments for these diseases are still elusive,

\footnotetext{
* Correspondence: kannan@bmb.uga.edu

${ }^{1}$ Institute of Bioinformatics, University of Georgia, Athens, GA 30602, USA

Full list of author information is available at the end of the article
}

and there remains an urgent need for deeper research into the basic biology of apicomplexans [2].

Several traits make these pathogens difficult to target therapeutically. As eukaryotes, they share a number of pathways with their mammalian and avian hosts; as intracellular parasites, they have been observed to quickly develop resistance to pharmaceutical treatments [3]. The identification of distinctive protein features which appear conserved across apicomplexan species, but not in their hosts, however, will aid the search for potential new targets for selective inhibition that are more likely to be safe and effective [4]. As protein kinases have been successfully targeted for inhibition in cancer, this diverse protein superfamily warrants consideration as a target for parasitic diseases as well $[2,5]$.
C Biomed Central

(c) 2011 Talevich et al; licensee BioMed Central Ltd. This is an Open Access article distributed under the terms of the Creative Commons Attribution License (http://creativecommons.org/licenses/by/2.0), which permits unrestricted use, distribution, and reproduction in any medium, provided the original work is properly cited. 
Recent whole-genome sequencing efforts have targeted a number of apicomplexan species [6-17]. Several analyses of protein kinases in these organisms, in particular, have pointed out key signaling pathways [18-20], instances of expansion and loss of kinase gene families $[21,22]$, and emergence of novel protein kinase families $[21,23,24]$, thus providing important insights into biological functions. These comparative studies have furthermore proposed hypotheses which have subsequently been validated by functional and structural studies $[19,20,25,26]$.

The eukaryotic protein kinase (ePK) superfamily is classified into several major groups, corresponding to broad functional categories with distinguishing sequence and structural features $[27,28]$. The presence of specific ePK groups and families in a genome is a key indicator of biological functions critical for an organism; likewise, missing groups or families indicate functions less critical for an organism's survival and reproduction. These proteins, and the fundamental cell processes in which they participate, are well characterized in humans and several model organisms [28].

Previous efforts to perform detailed comparative analysis of apicomplexan kinases have largely focused on the kinomes of individual species within the genera Plasmodium, Toxoplasma and Cryptosporidium $[10,11,20,29-32]$. Thus, there is no global overview of the sequence and structural features that distinguish apicomplexan kinases collectively from their metazoan counterparts.

Sequence data from 15 apicomplexan species and several crystallographic structures of a variety of apicomplexan protein kinases are now available. We can use these data to perform a systematic comparison of protein kinases in apicomplexans and model eukaryotes to identify broadly conserved orthologous groups and distinctive residue-level differences.

In this study we use a bioinformatics approach to comprehensively analyze genomic and structural data sets. We perform an exhaustive comparison of apicomplexan kinomes, providing broad coverage of the phylum. We also perform a quantitative, residue-level analysis of the differences between kinases within the Apicomplexa and those in model eukaryotes, in particular humans. We use a Bayesian method [33] to rigorously quantify sequence differences between homologous protein kinases in apicomplexans and other eukaryotes, and reveal contrastingly conserved features that were not apparent previously. Where possible, we then place these sequence features in structural context to postulate specific hypotheses for experimental testing.

Our specific findings include: (i) a detailed accounting of the lineages in which the apicomplexan-specific kinase families FIKK and ROPK appear; (ii) a unique apicomplexan-specific subfamily of cyclin-dependent kinases (CDK), orthologous to P. falciparum crk-5, and the motifs that distinguish it; (iii) a hypothesized mechanism of activation by phosphorylation, resembling that of MAP kinases, in a chromalveolate-specific subfamily of calcium-dependent protein kinases (CDPK); and (iv) a description of the adaptation of the substraterecognition and docking sites in the CLK kinase family in a clade including apicomplexans and other chromalveolates, revealed by the co-evolution of a small set of key residues.

\section{Results and Discussion}

We identified and classified the eukaryotic protein kinases in a total of 17 genomes from 15 species, as well as the solved apicomplexan ePK structures in the Protein Data Bank [34]. We used our classification to broadly describe the conserved ePK families in the Apicomplexa and then performed a residue-level analysis of the lineage-specific differences within several conserved families: CDK, CDPK and CLK. We place our findings in the context of the known evolutionary history of apicomplexans and their relatives.

\section{Kinome classification and composition: Variations within the Apicomplexa}

Recent published evolutionary relationships of eukaryotes provide the basis for our genomic comparison [35]. In this study we have chosen model organisms representing major evolutionary splits - the emergence of Chromalveolata (a proposed super-kingdom of plastid-containing eukaryotes [36]), Alveolata (the kingdom comprising ciliates, dinoflagellates and apicomplexans [37]), and Apicomplexa - to illuminate the origin and divergence of the major ePK groups. For genomic comparison we use the parasitic dinoflagellate Perkinsus marinus as an outgroup to the Apicomplexa, the photosynthetic diatom Thalassiosira pseudonana as an outgroup to the Alveolata, and the yeast Saccharomyces cerevisiae as an outgroup to the Chromalveolata. Detailed kinase annotations are given for each genome in Additional File 1.

\section{Apicomplexan kinome sizes are comparable to those of other unicellular protists}

The number of ePKs identified in each of the surveyed apicomplexan genomes varies, with the coccidians (Toxoplasma gondii, Neospora caninum and Eimeria tenella) containing more ePKs than the haemosporidians (Plasmodium spp.), and the piroplasms (Babesia bovis and Theileria spp.) containing fewer (Table 1). Cryptosporidium spp., the most basal group of apicomplexans considered here, contain a similar number of ePKs to Plasmodium spp. 
Table 1 Kinome sizes

\begin{tabular}{lccc}
\hline Species & ePKs & Genes & Ratio \\
\hline Plasmodium berghei & 69 & 4904 & $1.41 \%$ \\
Plasmodium chabaudi & 70 & 5131 & $1.36 \%$ \\
Plasmodium yoelii & 62 & 5878 & $1.05 \%$ \\
Plasmodium knowlesi & 65 & 5197 & $1.25 \%$ \\
Plasmodium vivax & 65 & 5435 & $1.20 \%$ \\
Plasmodium falciparum & 93 & 5491 & $1.69 \%$ \\
Theileria annulata & 42 & 3793 & $1.11 \%$ \\
Theileria parva & 43 & 4035 & $1.07 \%$ \\
Babesia bovis & 43 & 3671 & $1.17 \%$ \\
Toxoplasma gondii GT1 & 137 & 8102 & $1.69 \%$ \\
Toxoplasma gondii ME49 & 146 & 7993 & $1.83 \%$ \\
Toxoplasma gondii VEG & 133 & 7846 & $1.70 \%$ \\
Neospora caninum & 141 & 7082 & $1.99 \%$ \\
Eimeria tenella & 90 & 8786 & $1.02 \%$ \\
Cryptosporidium hominis & 65 & 3886 & $1.67 \%$ \\
Cryptosporidium parvum & 75 & 3805 & $1.97 \%$ \\
Cryptosporidium muris & 77 & 3934 & $1.96 \%$ \\
Perkinsus marinus & 251 & 23654 & $1.06 \%$ \\
Thalassiosira pseudonana & 140 & 11673 & $1.20 \%$ \\
Saccharomyces cerevisiae & 116 & 5797 & $2.02 \%$ \\
\hline Tota proteome and proten & &
\end{tabular}

Total proteome and protein kinome sizes in each genome. Columns indicate species name, the number of ePKs found using our method, the number of protein-coding genes in each genome, and the calculated proportion of ePKs in each genome for comparison. Atypical protein kinases are excluded from all ePK counts.

Taken as a percentage of total genome size, the proportions of kinases in apicomplexans are generally either comparable to the $2 \%$ observed in yeast and humans [28], as seen in the coccidians and Cryptosporidium, or reduced, as in the piroplasms and Plasmodium (Table 1). (Note that the quality of genome assemblies and gene model annotations varies, and these differences can affect the number of genes and kinases identified in each genome; the low kinase-togene ratios given for $P$. yoelii and E. tenella should therefore be interpreted with caution.) There is no evidence of the striking overall expansion of kinases seen in free-living ciliates such as Paramecium tetraulia (ePKs $6.6 \%$ of the genome [38]), which form a sister clade to Apicomplexa within the kingdom Alveolata. Rather, the number of kinases appears to scale with the total number of protein-coding genes in each genome, with small deviations.

Except for the coccidians and P. falciparum (which each contain dramatic expansions of novel kinase families, discussed below), the absolute number of kinases in each apicomplexan genome is markedly reduced relative to free-living eukaryotes (Table 1). The piroplasm kinome sizes, for instance, are less than twice the minimal kinome of 29 ePKs exhibited by another obligate intracellular parasite, Encephalitozoon cuniculi
[39]. The pattern of genome compaction, occasionally offset by lineage-specific expansions of specific gene families, has been noted as a common mode of genomic evolution in unicellular pathogens [40] and apicomplexans specifically [41,42]. Evidently, the ePKs have evolved according to some of the same adaptive strategies as the overall genomes of these parasites.

\section{Survey of ePK major groups}

We classified the kinases in each of the surveyed apicomplexans and model organisms according to a hierachical scheme based on seven major ePK groups, enabling a direct comparison of the group composition between kinomes (Figure 1). The CMGC and CAMK groups are especially well conserved across eukaryotes, indicating that the cell functions performed by these proteins are fundamental and essential for eukaryotic life. The casein kinase 1 group (CK1) is conserved in at least one copy among all eukaryotes as well. The tyrosine kinase (TK) and receptor guanylate cyclase (RGC) groups are entirely missing from the Apicomplexa, which has previously been noted $[24,43]$, as well as the three outgroup genomes. There is an apparent reduction, relative to the outgroup $P$. marinus and $T$. pseudonana, of the cyclic-nucleotide-and calcium/ phospholipid-dependent kinases (AGC group) in most of the Apicomplexa (Figure 1). The coccidians have between 9 and 13 members of the AGC group, while other apicomplexans have 3 to 5 AGC kinases; PKA is the only AGC family that is found in every genome (Additional File 1). The additional AGC members in coccidians appear as 1-3 copies of several known families, suggesting that AGCs were mostly lost in the other lineages and conserved or slightly amplified in coccidians, rather than a significant expansion in coccidians relative to the common ancestor. An even more dramatic loss of kinase families along all lineages is apparent in the STE group, which we discuss below. The tyrosine-kinase-like group (TKL) shows greater variation, appearing in some abundance in coccidians and Plasmodium spp. but absent from piroplasms, except for a single instance in T. annulata (Figure 1). The "Other" group designation collects all the ePK families that share the ePK fold and sub-domain architecture (unlike atypical protein kinases), but do not fall cleanly into any of the recognized major ePK groups found in the human kinome [28]. Many apicomplexan kinases fall in the Other group (Figure 1), reflecting their deep evolutionary divergence from humans, the reference genome for the commonly accepted kinase classification scheme [28]. Atypical protein kinases, such as the ABC and RIO families, were excluded from this analysis. 


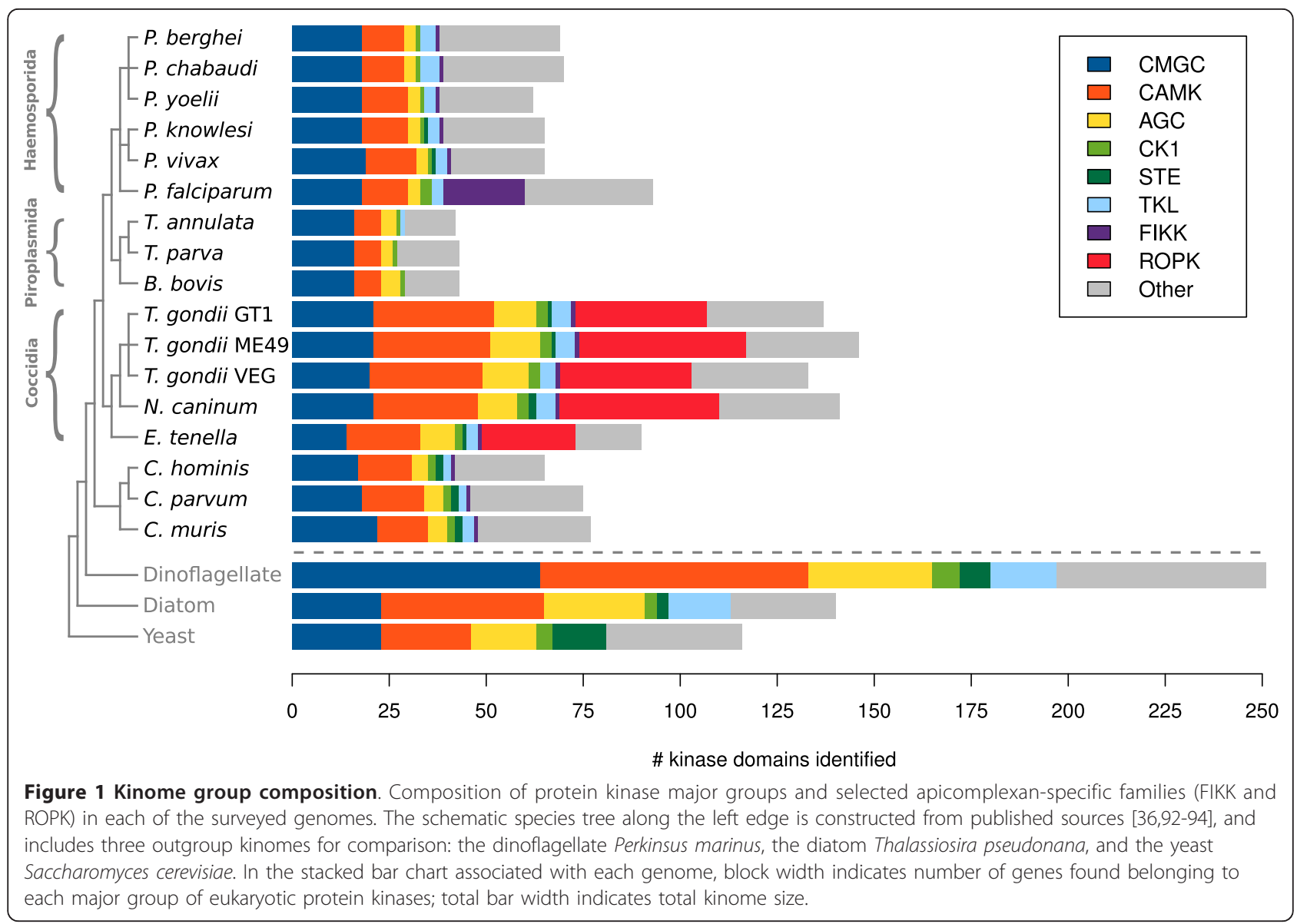

\section{Conservation of cell-cycle-associated kinases (CMGC) in chromalveolates}

The CMGC group is named after four protein kinase families it contains: cyclin-dependent kinase (CDK), mitogen-activated protein kinase (MAPK), glycogen synthase kinase (GSK), and cdc-like kinase (CLK, also called LAMMER) [28]. These kinases are involved in various aspects of cell cycle control, and are highly conserved throughout Eukaryota. Though apicomplexans, as obligate parasites, are able to depend on their host for survival, these signaling mechanisms for various aspects of cell cycle control are retained. Their life cycles are generally complex, often involving both a primary and a secondary host, encysted phases, and sudden trigger of reproduction and proliferation in response to some chronological or external stimulus [44]. This seems to suggest elaborate signaling and regulatory mechanisms, and points toward specialization of CMGC kinases in the Apicomplexa [21].

The most abundant family within the CMGC group is CDK; it is found in 3-6 copies in each apicomplexan genome, and 7-11 copies in the outgroup genomes (Additional File 2). The CDC2 subfamily of CDK is found in at least one copy in every genome, while some species contain single instances of additional CDK families. There are also 1-4 CDKs in each genome which could not be classified into known subfamilies, leaving open the possibility of lineage-specific adaptations in these unclassified copies. GSK occurs in 1-3 copies in each apicomplexan genome, and 1-5 in the outgroup genomes (Additional File 2), reflecting an essential and conserved role in cellular function. Likewise, MAPK and casein kinase II $\alpha$ (CK2) are present in a small number of copies in each of the apicomplexan and other eukaryotic genomes surveyed. The MAPK subfamily ERK7 is found in a single copy in every apicomplexan genome, while ERK1 is missing from Plasmodium spp. and the piroplasms. The RCK family, comprising the MAK and MOK subfamilies, is present in the three outgroup species but missing from the Apicomplexa.

The CLK and SRPK families, and some subfamilies of DYRK, are involved in phosphorylation of splicing factors such as SR proteins $[45,46]$. We found 2-4 DYRKs in each apicomplexan genome (Additional File 2). The most conserved subfamily of these, PRP4, was found in 
1 copy in each genome except $E$. tenella. A plant-specific subfamily of DYRK, called DYRKP, was found only in coccidians and the outgroups P. marinus and T. pseudonana. We found 1 copy of CLK in every surveyed genome, and SRPK in 1 copy in all except $P$. marinus, which has 3 copies.

The close relationship between CLK, SRPK and DYRK can confound homology-based classification attempts. However, the families can be distinguished by the presence of family-specific inserts [47] and by the replacement of the arginine in the kinase-conserved catalytic "HRD" motif with threonine ("HTD") in CLK and SRPK, and cysteine ("HCD") or alanine ("HAD") in various DYRK subfamilies [48]. The first comprehensive study of an apicomplexan kinome [21] identified 4 putative CLKs in P. falciparum, assigning the names PfCLK-1 through PfCLK-4. Our classification confirmed PfCLK-1 [EupathDB:PF14_0431] as a CLK (discussed in detail below). PfCLK-4 [EupathDB:PFC0105w] has recently been characterized as an SRPK [49]. We assigned PfCLK-3 [EupathDB:PF11_0156] to the PRP4 subfamily of DYRK, supported by the presence of the "HAD" motif in the catalytic loop and homology with putative PRP4 kinases in each of the other Plasmodium species. Our classifier placed PfCLK-2 [EupathDB:PF14_0408] in the CMGC group but did not find support for a more specific family. The portion of the sequence in kinase subdomain $\mathrm{X}$, which is broadly conserved as the "EHLAMMERILG" in CLKs [50], is "RFIYSIVSYIG" in PfCLK-2 - there is no sequence identity except for the C-terminal glycine. PfCLK-2 has the catalytic loop motif "HCD", characteristic of most DYRK subfamilies. The protein sequence also contains long inserts in the catalytic domain in the same locations as those of SRPK. A recent study of PfCLK-1 and PfCLK-2 [51] confirmed SR protein phosphorylation activity and found that PfCLK-1 is localized primarily to the nucleus of the cell, like most CLKs, but PfCLK-2 is found in both the nucleus and the cytoplasm, as has been observed in SRPKs in other eukaryotes [52]. We suggest that this protein is unique, with characteristics of both the SRPK and DYRK families, and that the regulatory functions suggested by typical CLK family members do not fully describe the roles of PfCLK-2 in the cell. The corresponding ortholog group in OrthoMCL-DB [53] [OrthoMCL:OG5_165485] is specific to the Plasmodium genus, further evidence that PfCLK-2 and its orthologs are paralagous to apicomplexan CLKs and have diverged significantly.

\section{Distribution of calcium signaling kinases (CAMK) in Eukaryota}

Calcium signaling plays an important role in eukaryotic cell biology. Calcium ions serve as important second messengers in signaling pathways, regulated by the calcium- and calmodulin-dependent kinase (CAMK) group [29]. In apicomplexans, calcium signaling regulates motility and other processes associated with host invasion [31].

There are multiple conserved CAMK members in each surveyed genome, though we observed more variation in gene family sizes here than in the CMGC group. We found 19-31 putative CAMK genes in each coccidian genome, 13-16 in Cryptosporidium spp., 11-13 in Plasmodium spp. and 7 in each piroplasm (Figure 1). The closely related dinoflagellate $P$. marinus has 69 putative CAMK genes, and the more distantly related diatom $T$. pseudonana has 42 . This points to a slight overall reduction of CAMK and CAMK-like protein kinases in coccidians, and more dramatic reductions in the other apicomplexan lineages, relative to the dinoflagellate and diatom (Figure 1). This follows with the overall conservation or reduction of total kinome sizes in each of the genomes (Table 1).

The calcium-dependent protein kinase (CDPK) family within CAMK is of particular interest, as its role in parasite invasion has been investigated recently by several teams $[19,54,55]$. Like plants and some other protists, apicomplexan genomes contain multiple members of the CDPK family [31]. We found 6 CDPKs in P. falciparum, 5 in each of the other Plasmodium species, 4-5 in the piroplasms, 11-14 in the coccidians and 7-9 in Cryptosporidium spp. In $T$. gondii and $N$. caninum there were also 7-10 members of the CAMK group that could not be classified into a known family. The greater number of CDPK copies and unclassified CAMKs in coccidians accounts for most of the apparent expansion of the CAMK group in that lineage relative to other apicomplexans.

\section{Loss and divergence of STE kinase families in apicomplexan lineages}

The STE group includes a variety of kinases which participate in MAPK signaling cascades upstream from the MAPK protein [28]. The key families in the group are STE20 (MAP4K), STE11(MAPKKK/MAP3K) and STE7 (MAPKK/MEK), which form a phosphoryl signaling cascade terminating with the phosphorylation of a MAPK on its activation loop at a conserved TxY motif [56]. This MAPK cascade is highly conserved in most eukaryotes, so it is surprising that the STE group has been largely lost from the Apicomplexa, as has been noted previously [21,57].

According to our analysis, the STE group is entirely missing from the piroplasms, while in the Plasmodium genus only $P$. knowlesi and $P$. vivax each retain a single STE gene which could not be further classified into a known STE family (Figure 1; Additional File 1). There were also unclassified STEs in T. gondii strains GT1 and ME49, E. tenella and Cryptosporidium spp. (Additional 
File 1). We did not find any STEs in T. gondii strain VEG.

The STE11 family was not found in any of the surveyed apicomplexan genomes. One STE20, showing closest resemblence to the FRAY subfamily (homologs of human OSR1), was found in N. caninum; the other apicomplexans had none. STE7 instances appear in $N$. caninum, C. hominis and C. parvum. For comparison, Perkinsus marinus contains 1 instance of STE11 and two instances of STE20, in the MST and PAKA subfamilies (homologs of human MST2 and PAK2, respectively) (Additional File 1). The ciliate Tetrahymena thermophila has multiple representives of STE11, STE20, STE7, and other STE families [58].

Features of the two MAPKs of P. falciparum illustrate how apicomplexans can compensate for the lack of a complete MAP signaling cascade. Pfmap-1 [EupathDB: PF14_0294] was identified as a member of the ERK7 family of MAPK [21], and retains the conserved TxY activation loop motif of most MAPKs. Pfmap-2 [EupathDB:PF11_0147], however, could not be assigned to a known MAPK subfamily in earlier analyses [21,57] or in ours. In Pfmap-2, the activation loop motif TxY is replaced by TSH [59], and we also note a long insert of about 26 amino acids in the activation loop N-terminal to the TSH motif. Orthologs of Pfmap-2 identified in OrthoMCL-DB [OrthoMCL:OG5_138034] appear in each of the apicomplexan genomes surveyed here, and also retain the long insert in the activation loop and a TSH or TGH motif in place of TxY. Pfmap- 2 has been shown to be phosphorylated and activated by the kinase Pfnek-1 [EupathDB:PFL1370w] [60], which is not a member of the STE kinase group but in this case appears to be nonetheless serving as a MAP kinase kinase. As with Pfmap-2, orthologs of Pfnek-1 appear in each of the surveyed apicomplexans [OrthoMCL: OG5_129446]. The conservation patterns of these kinases suggest that the observations made of $P$. falciparum's unique MAPK signaling mechanisms can be applied usefully to other apicomplexans.

\section{FIKK, an apicomplexan-specific protein kinase family}

FIKK is a divergent protein kinase family initially identified in P. falciparum, named for a conserved four-residue motif in the kinase subdomain II [21]. Previous studies have found 21 copies in P. falciparum and 6 in $P$. reichenowi, but single instances in other Plasmodium genomes, indicating rapid expansion along one branch within the genus [23]. In P. falciparum, FIKK proteins are generally exported to the host cell and often localized to the host cell membrane [61]. Recent work has found that some $P$. falciparum FIKKs are targeted to the Maurer's clefts, which are formed from or in connection with the parasitophorous vacuole membrane $(\mathrm{PVM})$ as a transport mechanism and eventually reach the host cell surface [62]. A variety of functional domains have also been discovered in the $\mathrm{N}$-terminal tail of the FIKK kinase domain, suggesting that the kinase domain and export signal allow trafficking of parasite proteins or other molecules to the host cell membrane [23].

In addition to the 21 recognized FIKKs in P. falciparum [21,23], we found a single copy of FIKK in every one of the surveyed apicompexan genomes except Theileria spp. and Babesia bovis (Figure 1). No homologs were found outside the Apicomplexa. The apparent absence of FIKK from the three piroplasm genomes is particularly intriguing. To rule out the possibility that this absence is simply the result of the FIKK gene model having not been included in the available proteomic sequences, we performed an additional search on the full set of translated ORFs from the genomic DNA sequence sets for these three species; again, no FIKK genes were found. The parsimonious conclusion is that the gene was lost along the piroplasmid evolutionary branch. This loss suggests there may be some difference in the physiology of piroplasmids that eliminates the need for the FIKK protein in those species.

We note with some interest that, in the process of entering a host cell, apicomplexans generally envelop themselves in a parasitophorous vacuoule constructed from the host cell membrane. (This is true of all of the species surveyed here.) Unlike Plasmodium spp. and most other apicomplexans, however, Babesia and Theileria species escape from their parasitophorous vacuole shortly after entering the host erythrocyte $[11,63]$. Thereafter, the piroplasm interacts directly with the host cell cytoplasm, rather than through the membrane of a vacuole, potentially simplifying the signaling machinery needed by the parasite. Piroplasms are also nonmotile and show other reduced functions compared to other apicomplexans [1]. However, more study of the role of FIKKs and the interaction between the PVM and host cell in apicomplexan species outside Plasmodium is needed in order to refine this hypothesis.

\section{ROPK family is specific to the coccidians}

The rhoptries are a collection of vesicular organelles within the apical complex, a distinguishing feature of the Apicomplexa. They appear in all of the apicomplexans surveyed here [1]. During the invasion process, a number of proteins contained in the rhoptries are secreted through the apical complex into the parasitophorous vacuole, and in some cases the host cell cytosol [64]. The rhoptry kinase family (ROPK) comprises the protein kinases targeted to the rhoptry. ROPKs play a major role in the infection mechanism of T. gondii [65]; they have been characterized in $T$. gondii and to a lesser extent in $N$. caninum [24]. The sequences of ROPKs are divergent from other ePKs, but most can still be 
recognized by generic protein kinase search profiles [24]. Most rhoptry kinases appear to be catalytically inactive, lacking at least one residue of the catalytic "KDD" triad (the lysine and asparates normally conserved in ePK subdomains II, VI and VII [27]), but kinase activity has been demonstrated in ROP16 and ROP18 [24,66]. Recent structural studies of ROP2 and ROP8 revealed a unique modification of the N-lobe of the kinase domain, in particular, and suggested important functional roles for these proteins, despite the absence of catalytic activity in these ROPKs [67].

We found the ROPK family only in the coccidian clade (Figure 1). Proteins associated with the rhoptries in other lineages appear to be unrelated to coccidian ROPKs or any other ePK families.

Our analysis included three strains of $T$. gondii, corresponding to the three classes of virulence: GT1 (Type I, high virulence), ME49 (Type II, intermediate virulence), and VEG (Type III, non-virulent) [68]. The most dramatic difference in kinase counts between the three strains of $T$. gondii appears in the ROPK family (Figure 1). We identified 40 ROPKs in T. gondii strain ME49, but 29 in GT1 and VEG (Additional File 1). A simple clustering of the sequences (data not shown) did not reveal a clear separation of ME49 ROPK genes that would indicate an expansion in ME49, so the discrepency may instead be due to losses in the other two strains, or simply differences in the quality of genome assembly and annotation.

\section{Sequence and structural features contributing to functional divergence}

Our approach revealed several novel and distinct subfamilies within recognized ePK families. Within each family, we then performed a phylogenetic analysis of the protein sequences of kinase domains from apicomplexans and several diverse model organisms to identify putative ortholog groups that include several apicomplexan species, but no metazoan species. (See Methods.)

Statistical analysis of the sequences using the CHAIN program revealed distinctive sequence and structural features which distinguish apicomplexan kinases from their homologs in other eukaryotes. Specifically, we used each identified apicomplexan-specific ortholog set as a query against a larger "main" set of sequences representing the corresponding kinase family (CDK, CDPK and CLK) taken from diverse eukaryotic species. CHAIN uses a Bayesian MCMC procedure to concurrently (a) partition the "main" set into a "foreground" of sequences that share distinct residue motifs found in the query, a "background" set of sequences that do not share those motifs, and an "intermediate" set that shares only some of the motifs; and (b) identify the alignment columns defining the motifs that distinguish the foreground and background sets [33]. We then used PyMOL [69] and a set of custom scripts leveraging Biopython [70] to map the most significant residue patterns onto aligned protein structures for comparative structural analysis.

Here we describe three proposed instances of lineagespecific divergence of apicomplexan kinases, within the CMGC and CAMK major groups, with an analysis of the sequence motifs and evolutionary histories that define them. Where crystallographic structures have previously been solved, we map sequence motifs onto the $3 \mathrm{D}$ structures to gain insight into possible regulatory mechanisms.

\section{Orthologs of Pfcrk-5 form a novel subfamily of cyclin- dependent kinases}

While each apicomplexan kinome contains multiple genes belonging to the cyclin-dependent kinase (CDK) family, we find a novel CDK subfamily which appears in a single copy in 14 of the 17 apicomplexan genomes surveyed, absent only from Cryptosporidium spp., and is not found outside Apicomplexa. This subfamily comprises the orthologs of $P$. falciparum Pfcrk-5 [EupathDB:PFF0750w]. This ortholog group is equivalent to a group in OrthoMCL-DB [OrthoMCL: OG5_150603], but with the addition of an ortholog we identified in Theileria parva [Genbank:TP04_0791]. A multiple sequence alignment of the subfamily kinase domains, including accession numbers, is given in Additional File 3.

The subfamily is distinguished by a unique PTxC motif in the activation loop (Pfcrk-5 positions 255-258), which is strikingly conserved relative to other CDK members in diverse eukaryotes, and absent from diverse eukaryotic homologs, as determined by CHAIN analysis (Figure 2; Additional File 4). In eukaryotic homologs, the residues at the location of the PTxC motif are most often histidine, glutamate and valine. The threonine in position 254 is also found as either threonine (usually) or serine (more rarely) in homologs; this site is equivalent to T160 in human Cdk2, where phosphorylation of this residue dramatically increases CDK catalytic activity, apparently stabilizing the substrate-binding site by forming a network of hydrogen bonds with surrounding side chains [71].

While T254 is conserved in most CDKs across Eukaryota, the apicomplexan-conserved residues P255, T256 and C258 are strikingly different from those in CDKs of other eukaryotes (Figure 2). In particular, T256 in this subfamily appears most often as a glutamate in other CDKs, including the closest-matching known CDK subfamily, CDC2, though it is not strongly conserved overall in eukaryotic CDKs. Given the similarity in chemical properties between glutamate and phosphothreonine, it is tempting to speculate that T256 is a phosphorylation 


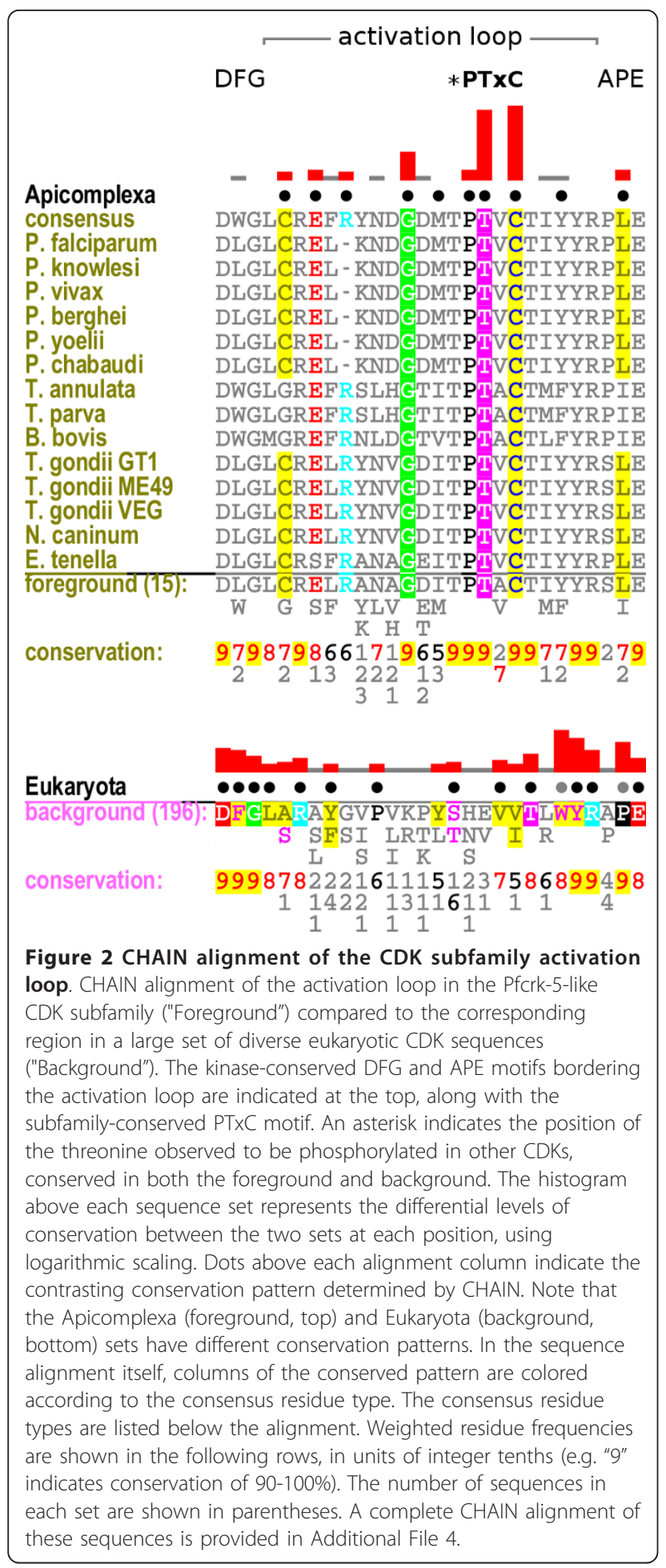

site in this subset of apicomplexan CDKs. An alternative hypothesis is that the residues in the PTxC motif may provide contact points for the substrate, as has been observed for the equivalent residues in the human homolog Cdk2 [72]. Human Cdk2 belongs to the CDK subfamily $\mathrm{CDK} 2$, not $\mathrm{CDC} 2$, but contains the motif HEVV in place of Pfcrk-5's PTVC, as most CDC2s do. In a solved structure of human Cdk2 [PDB:1QMZ], the residue V164, equivalent to $\mathrm{C} 258$ in Pfcrk-5, is located spatially between the bound substrate and the APE motif. It is possible that C258 in Pfcrk-5 and its orthologs packs hydrophobically against the equivalent region in this subfamily. This could also explain the co-conserved change of the APE motif to PLE (Figure 2). However, the absence of a solved 3D structure for any member of this subfamily prevents further analysis of the functional role of these residues. Although four structures of apicomplexan CDKs have been published [PDB:1V0O, PDB:1V0B, PDB:1OB3, PDB:2QKR], none of them correspond to genes from the Pfcrk-5 subfamily.

To assess whether the members of this putative subfamily should instead be assigned to the known CDK subfamily CDC2, we used CHAIN again to compare this subfamily to sequences representing the $\mathrm{CDC} 2$ subfamily. The same distinguishing pattern of PTxC in the activation loop appears in this comparison as well (Additional File 5). In P. falciparum, the CDKs Pfcrk-14 have all previously been annotated as "cdc2-related" kinases, and have been characterized in previous studies $[73,74]$. The canonical CDC2 in P. falciparum, as identified by our analysis, is protein kinase 5 [EupathDB: MAL13P1.279], which has the more typical "HEVV" motif in place of Pfcrk-5's "PTVC". Thus, the genes in this apicomplexan-specific subfamily appear to be paralogous to the known CDC2 subfamily, and may therefore have unique functional roles.

Distinct subfamilies of CDK are sometimes named after the conserved residue sequence in the cyclin-binding helix in the N-lobe of the kinase domain, known as the PSTAIRE helix in CDKs or more generally as the $\alpha \mathrm{C}$ helix in protein kinases $[71,73]$. In the proposed alveolate-specific subfamily the consensus sequence of the $\alpha \mathrm{C}$ motif is SCTTLRE, at Pfcrk- 5 sequence positions 93-99 (Figure 3). It is not yet known whether Pfcrk-5 is dependent on cyclin binding for activity, like PfPK5, Pfmrk and Pfcrk-3, or independent, like PfPK6 [73,74]. None of these residues appear in the CHAIN pattern, however, indicating that the individual residues at these positions may occur in some non-apicomplexan CDKs as well, and that this motif did not necessarily co-evolve with the activation loop motif that characterizes this apicomplexan-specific subfamily.

We also identify 5 large inserts in the kinase domain which are conserved to varying degrees across all 14 apicomplexan species, but not found in any other known subfamily of CDK. These inserts occur between subdomains I and II, III and IV, IV and V (in the coccidians), VII and VIII (after the conserved PLE, corresponding to 


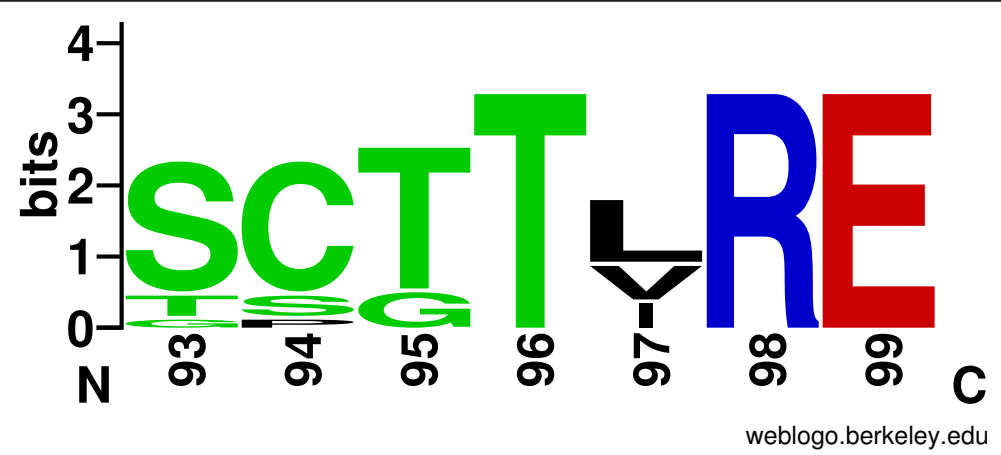

Figure 3 Logo of the CDK subfamily cyclin-binding motif. Logo of the aligned activation loop sequences in members of the Pfcrk-5-like CDK subfamily, generated by WebLogo [95]. Letter height represents information content; large letters indicated residues conserved within the subfamily.

APE in most ePKs, and extending over 100 amino acids in Plasmodium spp.), and X and XI (an extension of the CMGC insert, normally involved in substrate binding [48]). The inserts appear to be hydrophilic, and are generally conserved at the sequence level within each genus, but less clearly between different genera, indicating rapid evolution relative to the structurally conserved portions of the kinase domain.

\section{Features of a chromalveolate-specific CDPK subfamily point to a MAPK-like mode of regulation}

The CDPK family is characterized in green plants, and instances of it are also recognized in some protists (specifically, chromalveolates), but there are none in metazoans $[29,75]$ - this observation by itself encourages study of the CDPK family as a parasite-specific therapeutic target in human diseases. Each apicomplexan genome contains multiple CDPKs; we find and discuss a novel subfamily of these here. The subfamily is found in all of the surveyed apicomplexans as well as the dinoflagellate Perkinsus marinus, the ciliates Tetrahymena thermophila and Paramecium tetraulia, and the diatoms Thalassiosira pseudonana and Phaeodactylum tricornutum, indicating that the subfamily is shared by a clade within the Chromalveolata. It includes the $P$. falciparum protein PfCDPK5, which has been shown to play a key regulatory role during the parasite's blood stage [76]. The subfamily does not correspond cleanly to OrthoMCL-DB groups, but contains some members of the main CDPK group [OrthoMCL: OG5_126600] as well as some small lineage-specific groups (e.g. [OrthoMCL:OG5_170347]). Additional File 6 contains a multiple sequence alignment of the kinase domains of all 76 identified subfamily members.

CHAIN analysis highlighted several key residues that distinguish this subfamily from the larger set of chromalveolate CDPKs (Additional File 7), of which two are most striking: an arginine in the $\alpha \mathrm{C}$ helix, and a threonine or serine in the activation loop. The conservation of these two residues within the subfamily, but not in the broader CDPK family, suggests they have evolved under a shared functional constraint. Notably, the structure of a member of the subfamily in C. parvum, CpCDPK2 [EupathDB:cgd7_1840], has been solved in complex with an inhibitor [PDB:3F3Z] and in apo form [PDB:2QG5] [32]. The distinguishing residues numbered according to the crystal structures of CpCDPK2 are R69 and T184. Guided by CHAIN analysis, we compared these structures with that of another $C$. parvum CDPK outside the subfamily, CpCDPK1 [EupathDB:cgd3_920, PDB:3DFA], to understand the sequence and structural basis for possible C. parvum CDPK functional divergence.

We analyzed the structural interactions associated with R69 and T184 in the two available crystal structures of CpCDPK2 [PDB:2QG5, PDB:3F3Z] (Figure 4). In one of the CPCDPK2 structures [PDB:2QG5], R69 adopts two distinct conformations (Figure 4B-D). In chain A, R69 is positioned to form a hydrogen bond to the backbone of a residue (D66) at the $\alpha \mathrm{C}$ helix N-terminus, while in chain D, R69 appears to form a $3.1 \AA$ hydrogen bond to the backbone of the DFG motif glycine, located at the $\mathrm{N}$-terminus of the activation segment. In chain B, R69 is oriented outward, in a solventexposed position. (While the CPCDPK2 structure is presented as three chains, the biological unit has not been described.) B-factors and the different orientations of this residue in each chain indicate that the R69 side chain is flexible in this structure.

In the other CpCDPK2 structure [PDB:3F3Z], R69 is oriented toward the side-chain of T184, separated by a distance of $6.0 \AA$. Previous reports show that threonine autophosphorylation in the activation loop is prevalent in apicomplexan CDPKs $[30,54]$. We therefore hypothesize that this threonine $\left(\mathrm{T} 184^{2 \mathrm{QG5}, 3 F 3 Z}\right)$ could also serve as a phosphorylation site in the alveolate-specific CDPK subfamily. 


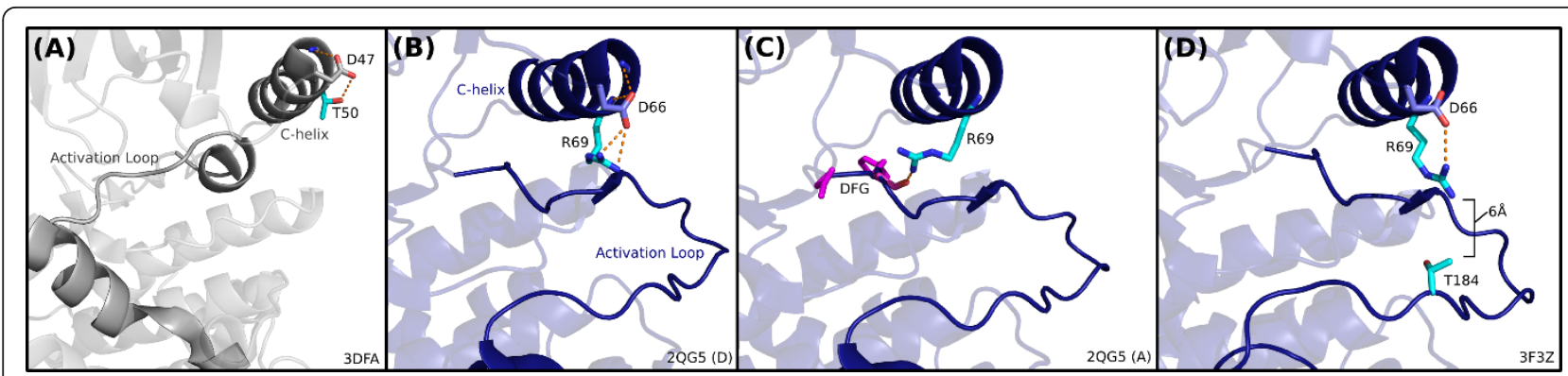

Figure 4 CDPK subfamily roles of $\alpha \mathrm{C}$ helix arginine and activation-loop threonine. Structures of several different CDPKs in C. parvum, demonstrating several proposed interactions for the $\alpha$ C helix arginine distinctive of an alveolate-specific CDPK subfamily. (A) A member of the background set of CDPKs [PDB:3DFA] has a threonine (T50), shown in cyan, in position to form a hydrogen bond with an aspartate (D47), gray, which caps the $\alpha$ C helix. This threonine corresponds to the subfamily-conserved arginine; however, the threonine here is not conserved in the background set of CDPKs. (B) In a structure of a member of the CDPK subfamily [PDB:2QG5], the subfamily-conserved arginine (R69, cyan) appears similarly positioned to interact with the aspartate (D66, blue) at the end of the $\alpha$ C helix, potentially stabilizing the cap. (C) Chain A of the same structure shows the distinctive arginine oriented inward, capable of hydrogen-bonding with the kinase-conserved DFG motif (side chains colored magenta). (D) In another structure of the same CDPK-subfamily protein [PDB:2QG5], the arginine is positioned toward a subfamily-conserved threonine in the activation loop (T184), shown in cyan. The distance between the R69 and T184 side chains is 6A, which could accomodate a phosphate group attached to the threonine and a hydrogen bond between the phosphothreonine and the arginine.

\section{Shared features of MAP kinases suggest a common regulatory mechanism}

To obtain additional insights into the role of R69 and T184 in CpCDPK2 functions, we identified and analyzed crystal structures of kinases that contain both an $\alpha \mathrm{C}$ arginine and an activation-loop threonine at positions equivalent to CpCDPK2 R69 and T184, respectively. To allow for the flexibility and variable length of the activation loop, we also examined positions adjacent to T184. This revealed a large number of MAPK structures, including human and mouse p38, where a $\alpha \mathrm{C}$-helix arginine (R67) and activation-loop threonine (T180) appear to perform roles analogous to those proposed for R69 and T184 in CpCDPK2. In a crystal structure of p38 $\alpha$ [PDB:3NNX], R67 (equivalent to R69 in CpCDPK2) hydrogen bonds with the glycine backbone of the DFG motif at a distance of $2.8 \AA$, in a manner analogous to CpCDPK2. Another structure of $\mathrm{p} 38 \alpha$ complexed with a different inhibitor [PDB:3NNV] shows a similar interaction occurring at $3.2 \AA$. In a structure of mouse p $38 \alpha$ [PDB:3PY3], phosphorylated on both a threonine (T180) and a tyrosine (T182) in the activation loop, the $\alpha \mathrm{C}$ arginine (R67) coordinates with the phospho-threonine (Additional File 8). Thus the conserved arginine functions as a switch: upon phosphorylation, the activationloop phospho-threonine interacts with the $\alpha \mathrm{C}$ arginine, promoting inter-domain closure and stabilizing the $\alpha \mathrm{C}$ helix in an active conformation [77]. An equivalent mechanism has been described for p38 $\gamma$ [PDB:1CM8] as well [78].

The phosphorylated threonine in p38 corresponds to the TxY motif which is conserved across MAPKs [56], including JNK and ERK1. A sequence alignment of CpCDPK2 and PfCDPK5 along with human p38, JNK1 and ERK1 (Additional File 9) shows that the CDPK subfamily-conserved threonine is centered on the MAPK TxY motif. Another threonine, located 4 residues $C$ terminal to this site, is broadly conserved in both MAPK and CDPK.

We draw parallels between the observed conformations of CpCDPK2 and p38. An analogous role for R69 and $\mathrm{T} 184$ in $\mathrm{CpCDPK} 2$ would suggest a regulatory mechanism wherein phosphorylation of T184 leads to kinase activation by repositioning R69 from a DFG-stabilizing or solvent-exposed orientation toward the activation loop, consequently moving the regulatory $\alpha \mathrm{C}$ helix in an active conformation.

In a paralogous $C$. parvum CDPK that does not belong to the CPCDPK2 subfamily, CDPK1 [PDB:3DFA, EupathDB:cgd3_920], the $\alpha \mathrm{C}$ arginine is replaced by T50, and the activation loop threonine by D165 (Figure 4A). Rather, the interactions described here are distinctive of the alveolate-specific subfamily of CDPKs including CPCDPK2. The minor expansion of the CDPK family in chromalveolates has created an evolutionary opportunity for certain copies of CDPK genes to subfunctionalize, adapting the additional regulatory role for promoting phosphorylation-dependent inter-domain closure.

\section{Lineage-specific mechanisms of substrate recognition and} binding in CLK

Within the CLK family, we again find a residue pattern that distinguishes chromalveolate CLKs from those in all other eukaryotic lineages. This pattern appears in all apicomplexans surveyed, as well as several dinoflagellates, ciliates, diatoms, and the brown alga Ectocarpus siliculosus (Additional File 10). The phyletic distribution 
of this set of co-conserved motifs points to an origin near the base of Chromalveolata, prior to the emergence of alveolates, and a deep evolutionary divergence between chromalveolates and metazoans.

These chromalveolate CLKs are distinguished most prominently by residues in the substrate-recognition and docking sites (Additional File 11). Numbered according to the representative $P$. falciparum protein serine/threonine kinase 1 [EupathDB:PF14_0431], also called PfLAMMER [79], the distinguishing residues include Q739, L772 and R775 in the primary docking site, N736 and S755 in the secondary substrate-recognition site, and the acidic residue D653 in the $\alpha \mathrm{E}$ helix (Figures 5, 6 and 7; discussed below). Taken together, this set of amino acid differences represents a statistically significant partition between chromalveolate and other eukaryotic CLK sequences.

A crystallographic structure of PfLAMMER is available [PDB:3LLT], but has not been previously discussed in detail. We compared this structure to two human CLK homologs, Clk1 [PDB:1Z57, PDB:2VAG] and Clk2 [PDB:3NR9], as well as human SRPK1 [PDB:1WAK], to predict structural and functional roles of the lineagespecific residues. A PyMOL script to visualize the structures of PfLAMMER, Clk2 and Clk3 is provided as Additional File 12.

\section{Mechanisms of substrate recognition, binding and processive phosphorylation}

The typical substrate of CLK is an SR protein, characterized by an N-terminal RNA-binding domain and an unstructured C-terminal tail of varying length, called the RS domain, which is enriched in arginine and serine, often occurring as "RS" dipeptide repeats [45]. The SR proteins in a cell play multiple roles in spliceosome formation and mRNA splicing activity, including regulation of alternative splicing $[80,81]$. CLKs are closely related to SRPKs, which also phosphorylate the RS domain of SR proteins. Both kinases are constitutively active, and perform processive phosphorylation on the RS domain of an SR protein substrate, proceeding in the carbonylto-amino direction along the substrate peptide [82]. However, differences in substrate binding and the extent of RS domain phosphorylation between SRPK and CLK allow interplay between these proteins to affect the activity and subcellular localization of the SR protein in a complementary fashion [83]. Thus, the complementary regulation of SR proteins by CLK and SRPK has an important functional impact on mRNA splicing in the cell [49].

Substrate-recognition site Three residues responsible for initial recognition of the substrate, Q739, L772 and R775, are contrastingly conserved within the chromalveolate clade (Figure 5). In human Clk2, the equivalent residues H346, T379 and E382 form the substraterecognition site, with the histidine interacting with the substrate $\mathrm{P}-2$ residue ( $\mathrm{P}$ indicates the phosphorylatable residue), preferentially selecting for glutamate [47]. In PfLAMMER the histidine is replaced by a glutamine; the change in chemical properties suggests a different substrate preference for the protein. Additionally, in human Clk2 the three conserved residues form hydrogen bonds with each other and with a nearby F381 (Figure 5B); in PfLAMMER, Q739 only potentially forms a hydrogen bond with nearby residue T776, while L772 appears in

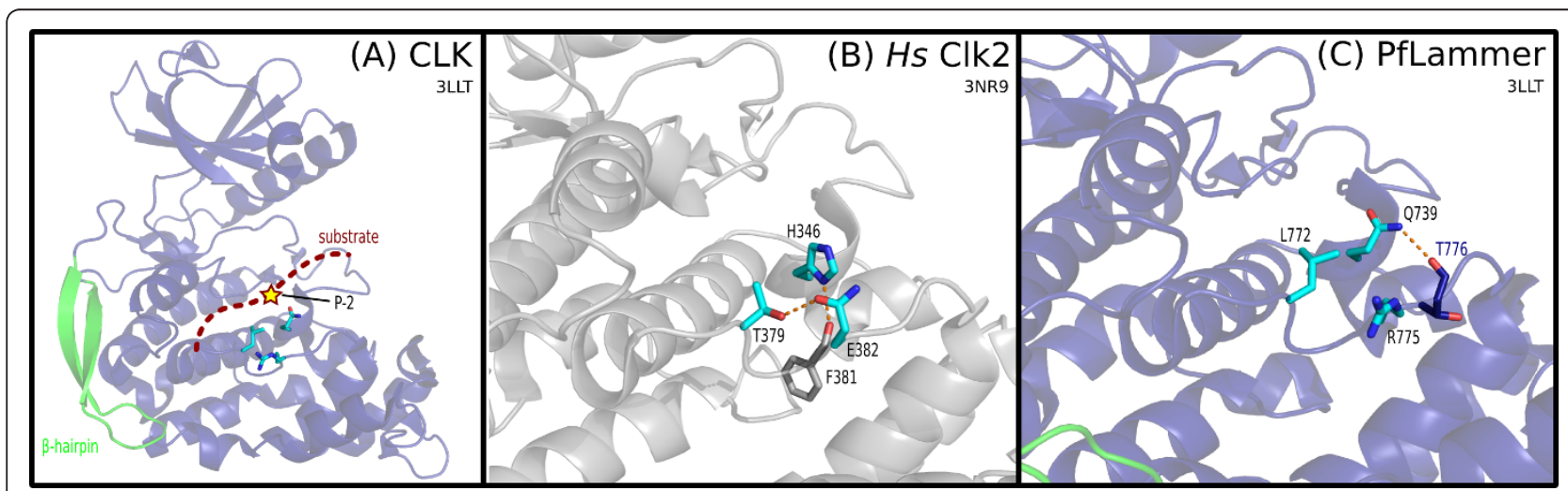

Figure 5 CLK docking site. Three contrastingly conserved residues involved in substrate recognition and docking in human Clk2 [PDB:3NR9] and the P. falciparum CLK, PfLAMMER [PDB:3LLT]. (A) Global view of the docking site, illustrating the position of the substrate RS domain and phosphorylation site. The contrastingly conserved resides are shown in cyan. (B) Human Clk2. A trio of constrastingly conserved residues (cyan), along with a nearby phenylalanine (gray), form a network of hydrogen bonds. The conserved histidine (H346) is positioned to interact with the substrate P-2 position. (C) In PfLAMMER, the three residues (cyan) are conserved as different types. A glutamine (Q739) replaces the histidine in human Clk2 seen to interact with the substrate P-2 position. The hydrogen bonding network is different: A leucine (L772) replaces the threonine seen in Clk2; an arginine (R775), corresponding to a glutamate in Clk2, is directed away from the other two conserved residues; and the glutamine (Q739) instead forms a hydrogen bond with a nearby threonine. 


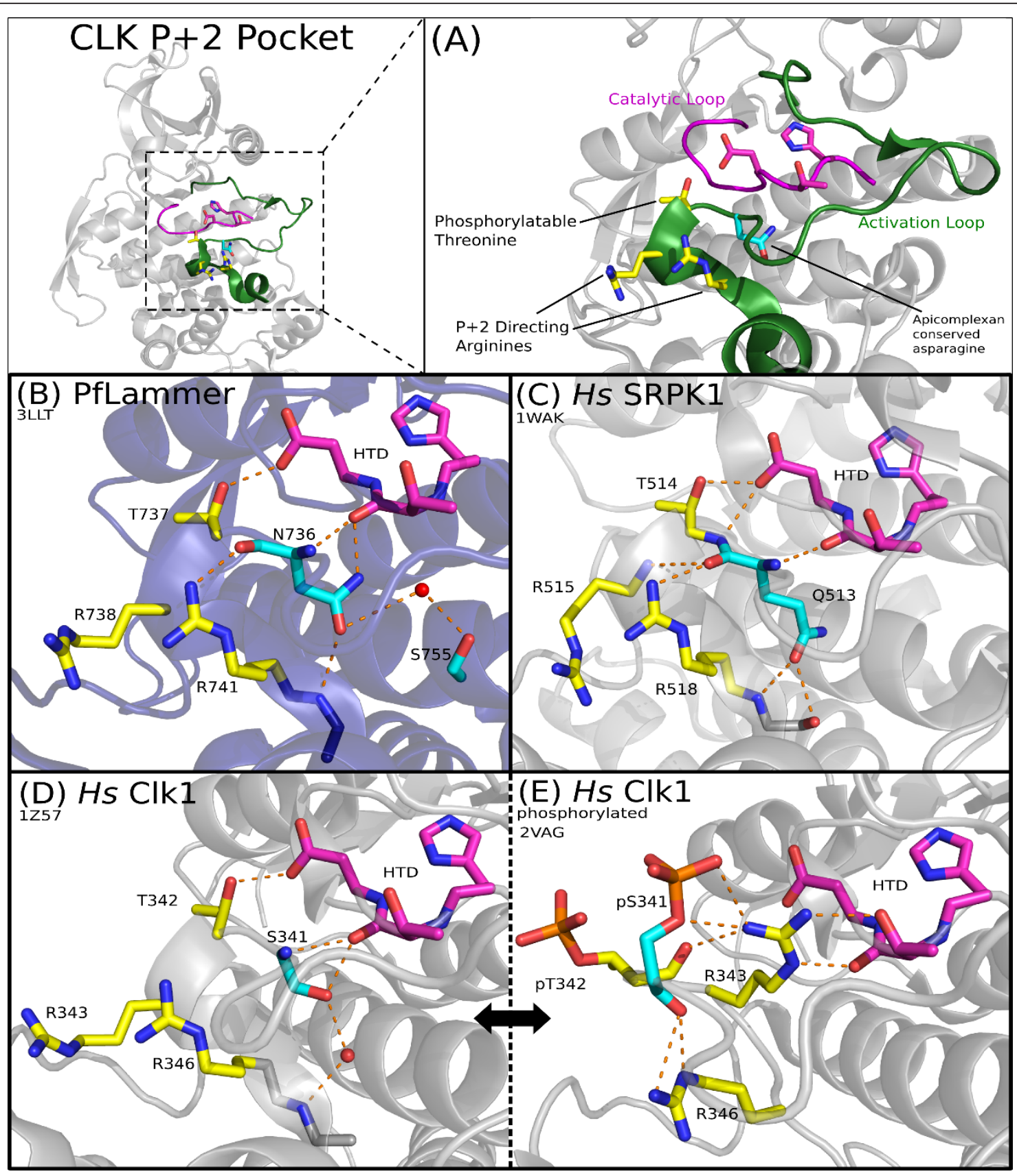

Figure 6 CLK coordination of substrate-binding and catalytic regions. Interactions between key residues in the substrate-binding region and the catalytic HTD motif are mediated by conserved residues in the activation loop. (A) Structural context of features in PfLAMMER [PDB:3LLT], showing the activation loop in green and the catalytic loop in magenta. Conserved residues are displayed in "sticks" representation. A contrastingly conserved asparagine, distinctive of chromalveolate CLKs, is indicated in cyan, and three other residues conserved throughout the CLK family are shown in yellow. (B) In PfLAMMER, the distinctive asparagine (N736) forms hydrogen bonds with the CMGC-conserved arginine (R741), the backbone of the alanine in the APE motif, the backbone of the threonine in the catalytic HTD motif, and, mediated by a water molecule, a subfamily-conserved serine in the $\alpha \mathrm{F}$ helix. (C) In human SRPK1, several of the hydrogen bonds formed by the glutamine Q513 are analogous to those formed by the N736 in apicomplexans. (D) and (E) Two structures of human Clk1. In the unphosphorylated structure [PDB:1Z57], left, the serine corresponding to PfLAMMER N736 (S341) and the adjacent CLK-conserved threonine (T342) are oriented in an "in" conformation, interacting with the catalytic motif (HTD) but not with the conserved arginines (R343, R346). In the phosphorylated structure [PDB:2VAG], right, the serine (pS341) and threonine (pT342) are flipped to an "out" conformation, breaking the interaction with the catalytic motif. One arginine (R343) moves to occupy the area vacated by the phosphorylated serine S341, while the other (R346) now interacts with the backbone of the phosphorylated serine. Phosphates are shown in orange. Images of PDB structures were rendered using PyMOL [69]. 


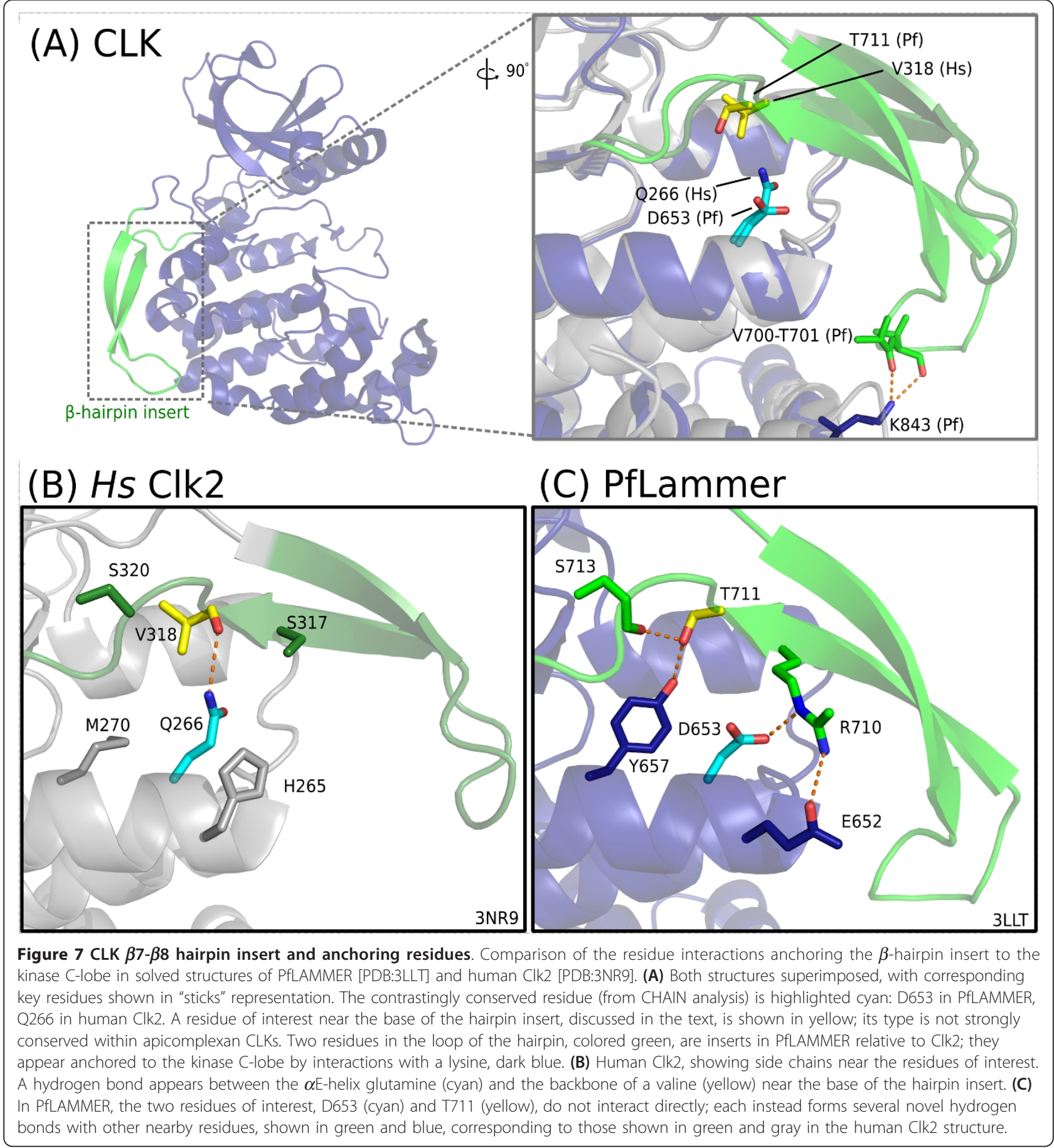

place of human T379, losing the bond (Figure 5C). The E382 in Clk2 is replaced in PfLAMMER by R775, which does not form hydrogen bonds with the nearby trio of substrate-recognition residues but is instead oriented outward, free to interact with other atoms, such as the substrate (Figure 5C). The location of the residues L772 and R775 in the loop connecting the $\alpha \mathrm{F}$ and $\alpha \mathrm{G}$ helices, in particular, is also significant because the $\alpha \mathrm{F}-\alpha \mathrm{G}$ loop is also involved in substrate binding; it is therefore likely that the chromalveolate-specific variations observed in this loop also contribute to a difference in substrate recognition.

$P+1$ binding pocket As mentioned above, apicomplexan CLKs have conserved lineage-specific residues located at the substrate-binding pocket. One such residue is a the chromalveolate-specific asparagine (N736) in the P+1 
pocket. N736 is conserved as a glutamine in SRPKs, as a serine in human Clk1 and Clk2, as a cysteine in GSK, and as a valine in CDK [48]. These variations may contribute to the substrate specificity by subtly altering the geometry of the $\mathrm{P}+1$ pocket. Alternatively, the variation observed at the $\mathrm{P}+1$ pocket may reflect the unique mode of allosteric coupling between the substrate-binding site and active site in CMGC kinases. Notably, both the backbone and side-chain of N736 in PfLAMMER are involved in hydrogen bonding to the backbone of the catalytically important HTD motif (Figure 6B), while in other CMGC kinases, the coupling between the $\mathrm{P}+1$ pocket and catalytic site is largely mediated through backbone hydrogen bonds (Figure 6C,D).

We used the program Coot [84] to examine N736 in the structure of PfLAMMER and found that its backbone conformation lies in a disallowed region of the Ramachandran plot, indicating that torsion-angle strain occurs here. This position has been reported to be in a strained position in SRPK1 and other CMGCs prior to substrate binding; substrate binding relieves this strain, highlighting the importance of this residue in the substrate binding mechanism [48]. It is also significant that in one of the human Clk1 structures [PDB:2VAG] (Figure 6E), S341 (equivalent to N736 in PfLAMMER) and T342 are phosphorylated, which dramatically alters the geometry of the $\mathrm{P}+1$ pocket and inactivates the kinase [85]. This indicates that the $\mathrm{P}+1$ pocket is conformationally malleable and can contribute to the unique modes of allosteric regulation.

Proline-directed and processive phosphorylation The CLK family, and related members of the CMGC group, conserve several distinctive residues in the substratebinding site that contribute to the substrate specificity of CMGC kinases. One such residue is the distinctive CMGC-arginine [48] (R741 in Figure 6B) located at the $\mathrm{C}$-terminal end of the activation loop. The CMGC-arginine contributes to substrate specificity by creating a favorable hydrophobic environment for a proline at the $\mathrm{P}+1$ position of the substrate. Specifically, the CMGCarginine caps the backbone carbonyl oxygen of a residue (N736 in PfLAMMER) in the $\mathrm{P}+1$ pocket that typically hydrogen bonds to the backbone amide of a residue at the $\mathrm{P}+1$ position. Because proline lacks a backbone amide, the capping of carbonyl oxygen by the CMGCarginine allows selective binding of substrates with proline at the $\mathrm{P}+1$ position [72]. The presence of the CMGC-arginine and the hydrogen bonds in the $\mathrm{P}+1$ pocket of PfLAMMER (Figure 6C) suggest that chromalveolate CLKs, like other CMGC kinases [45,86], are likely to be proline-directed.

PfLAMMER also conserves the P - 2 arginine (R738 in Figure 6C), which in human CLKs and SRPKs contributes to the processive phosphorylation of substrates by stabilizing a phosphorylated serine or threonine at the $\mathrm{P}$ - 2 position in the substrate $[47,48]$. This feature suggests that chromalveolate CLKs, like human and plant CLKs and SRPKs, may processively phosphorylate substrates with phosphorylatable serine or threonine at the $\mathrm{P}-2$ position. Indeed, a search for protein sequences with an RNA-binding domain [Pfam:RRM_1] and "RS" repeat regions identified at least three possible SR proteins in P. falciparum [EupathDB:PF10_0217, PFE0865c, PFE0160c], each with orthologs in other apicomplexan species [OrthoMCL:OG5_127971, OG5_128933, OG5_127418].

\section{Chromalveolate-specific features in the distal substrate- recognition site}

The CLK family, as it appears in all eukaryotes including apicomplexans, has a characteristic $\beta$-hairpin insert in the $\mathrm{C}$-lobe between the $\beta 7$ and $\beta 8$ strands, which blocks its SR protein substrate from docking in what is a distal substrate-recognition groove in other CMGCs (such as the MAP kinase p38) [47]. Blocking this docking interaction is critical for CLK substrate specificity, the primary means by which CLKs are regulated [47].

CHAIN analysis revealed a strikingly conserved acidic residue (aspartate or glutamate) in the $\alpha \mathrm{E}$ helix of chromalveolate CLKs which in other eukaryotic CLKs is generally a histidine or a glutamine. This difference is reflected in the anchoring of the $\beta$-hairpin insert to the C-lobe of the kinase domain (Figure 7). In PfLAMMER, the conserved acidic residue is D653; the equivalent residue in human Clk2 [PDB:3NR9] is Q266. In Clk2, the MAPK substrate-recognition groove is occupied by a hydrophobic V318; Q266 stabilizes the backbone of V318 in human Clk2 (Figure 7B). In contrast, the distinctive D653 in PfLAMMER participates in a network of hydrogen bonds involving an arginine in the $\beta$-hairpin insert; the V318 in Clk2 is replaced by $\mathrm{T} 711$, which itself forms hydrogen bonds with two other residues in the $\alpha \mathrm{E}$ helix and at the base of the insert, rather than with D653 (Figure 7C). Together these changes appear to further stabilize the beta-hairpin insert in P. falciparum by forming additional interactions. The changes also make the pocket more hydrophilic relative to $\mathrm{Clk} 2$.

The $\beta$-hairpin insert is several residues longer in chromalveolate CLKs than in human Clk2. In the PfLAMMER structure [PDB:3LLT], the hairpin loop is also anchored to the kinase $\mathrm{C}$-lobe by a hydrogen bond between a lysine (K843) in the C-lobe and the backbone of the hairpin loop - this lysine, and consequently the hydrogen bond, is not seen in human Clk2 (Figure 7A). However, it is also possible that the interaction occurs in the solved structure as a consequence of crystal packing, in which case there may be no functional significance in vivo. 
These variations, along with the variations in the primary substrate-binding site, indicate that apicomplexan and other chromalveolate CLKs have diverged from their human counterparts and specifically recognize and phosphorylate selected protein substrates.

\section{Conclusions}

We have used an approach based on evolutionary analysis to identify statistically distinct subfamilies of CDK and CDPK in the Apicomplexa and Chromalveolata, and explore the structural adaptations of CLK for substrate binding among chromalveolates. We discussed the functional implications of these distinguishing variations, confirmed and clarified previously published results regarding protein kinases in apicomplexan species, and proposed a set of new testable functional hypotheses, which we hope will focus future experimental efforts.

This methodology has provided a means for identifying clade-specific sequence and structural features which may be associated with functional specialization. We presented three well-supported lineage-specific groups of kinases that emerged from our analysis, supported by existing structural and functional data about related proteins, and inferred additional functional hypotheses and the mechanisms that might enable these functions. Two of these sub-groups are members of the CMGC kinase group, which is highly conserved across Eukaryota, allowing strong homologies to be drawn between extant species to reveal ancient divergences along evolutionary branches. The third family, CDPK, is largely specific to plastid-containing eukaryotes in the Chromalveolata and Viridiplantae (but also found in other protozoans), but is also relatively more highly duplicated in each genome; the additional gene copies enhanced the statistical support for a proposed subfamily. The public availability of whole-genome sequences from diverse apicomplexan species likewise enabled the detection of deeply conserved sequence patterns. The work of the Structural Genomics Consortium [87] has also been invaluable in providing structural evidence for this neglected branch of protozoa.

Not every eukaryotic protein kinase family in apicomplexans yielded a distinctive feature set, however. Many of the "Other" kinase families are difficult to classify precisely; some are lineage-specific, and some have a mix of sequence features shared by multiple kinase families - the PfPK7 family, in fact, presents both problems [18]. The previously identified apicomplexan-specific families, FIKK and ROPK, are not strong candidates for CHAIN analysis, either: Since all of the species containing these families belong to the same phylum, shared sequence features within a sub-clade are likely to be the result of recent common ancestry rather than functional constraints on their molecular evolution.
Despite these limitations, the approach we have presented will be useful for further analysis of apicomplexans as additional whole-genome sequences and protein kinase structures become available.

In the search for potential therapeutic targets for parasitic diseases, identification of these features and the molecular mechanisms they represent could lead to potential candidates for selective targeting. The taxonomic distribution of these novel protein features also provides insight into the evolution of apicomplexans and chromalveolates, lending support to the current understanding of these species' history.

\section{Methods}

\section{Genome data sources}

The protein complements of 17 complete genomes, from 15 distinct apicomplexan species, were retrieved from EupathDB [88]. The genomes of three non-apicomplexan species were also obtained for comparison (Table 2).

To obtain a sequence set of all solved apicomplexan ePK structures, the August 2011 release of PDBAA, the protein sequence database derived from $\mathrm{PDB}$, was downloaded from NCBI. Phylum labels were added to the sequence headers according to GI number using the NCBI taxonomy data set, and sequences from the phylum Apicomplexa were selected.

\section{Identification, classification and alignment of eukaryotic protein kinases (ePKs) in selected genomes}

We constructed a curated set of ePK family profiles using previously annotated sequences from diverse model organisms. The classification scheme is based on the kinase groups and families described in previous kinomic analyses $[27,28,89]$. Additional profiles for the FIKK, ROPK and PfPK7 families were built from apicomplexan sequences with annotations supported by experimental studies in published literature [21,24].

We used the MAPGAPS program with the curated profile sets to identify, classify and align the protein kinases in the genomic sequences, as well as the apicomplexan ePK structures in PDB. MAPGAPS selects all sequences with a kinase domain containing key motifs, assigns each sequence with a significant hit to the best-matching family in the query profile, and accurately aligns each hit to the kinase consensus sequence, capturing conserved motifs [90]. Fragmentary sequences were then deleted.

Identification and classification of the ePKs in each genome revealed certain families present in multiple copies, providing enough data for further comparative analysis. The sequence counts in this scan generally agree with previously published kinome analyses, though because these and most previous annotations are 
Table 2 Genome sources

\begin{tabular}{|c|c|}
\hline Genomes & Source \\
\hline $\begin{array}{l}\text { Plasmodium berghei ANKA, P. chabaudi AS, P. falciparum 3D7, P. knowlesi } \mathrm{H}, P \text {. } \\
\text { vivax Salvador I, P. yoelii 17XNL }\end{array}$ & PlasmoDB v.8.0 [6-10,96] \\
\hline Babesia bovis T2Bo; Theileria annulata Ankara, T. parva Mugaga & PiroplasmaDB v.1.1 [11-13] \\
\hline $\begin{array}{l}\text { Neospora caninum; Toxoplasma gondii GT1, ME49, VEG; Eimeria tenella } \\
\text { Houghton }\end{array}$ & ToxoDB v.7.0 [97] \\
\hline Cryptosporidium hominis, C. muris, C. parvum lowa II & CryptoDB v.4.5 [14-16] \\
\hline Perkinsus marinus ATCC 50983 & NCBI genome project 12737 \\
\hline Thalassiosira pseudonana CCMP1335 & NCBI genome project $34119[98,99]$ \\
\hline Saccharomyces cerevisiae & $\begin{array}{l}\text { Kinbase (http://kinase.com/kinbase/), Saccharomyces Genome } \\
\text { Database (http://yeastgenome.org/) }\end{array}$ \\
\hline
\end{tabular}

produced by different computational methods there is occasional disagreement over the classification of more divergent sequences lacking clear orthologs in model organisms.

\section{Gene tree inference to find divergent apicomplexan ortholog groups}

Within each assigned ePK family, we concatenated the three sequence sets (apicomplexan genomic; a profile of sequences from model organisms including human; apicomplexan $\mathrm{PDB}$ sequences) and realigned the kinase domains using MAPGAPS to prepare a sequence alignment for phylogenetic analysis. To infer a gene tree from each of these alignments, we used RAxML with the fast bootstrap and maximum likelihood tree estimation procedure [91], PROTGAMMAWAG model (WAG amino acid substitution model with the rate heterogeneity), and 500 bootstrap replicates. We then used a custom script based on Biopython [70] to collapse branches with less than $50 \%$ bootstrap support in the resulting gene trees.

A resolved clade in the gene tree containing sequences from a monophyletic group of species, in agreement with the established species tree, indicates that the genes are orthologous. We selected clades that contained sequences from several apicomplexan species, but did not include any metazoan sequences, and with particular interest in clades containing PDB structures, for further analysis.

\section{Patterns of functional divergence}

We queried related families of diverse sequences with selected clusters using the CHAIN program [33]. For each apicomplexan-specific cluster, we used the sequences from each gene clade of interest (described above) as the query set, and the sequences of diverse eukaryotic species in the corresponding kinase family as the main set, constructed from all kinase family members found in NCBI-nr. Both the query and main sequence sets were aligned with MAPGAPS for comparison.
The Bayesian Pattern Partitioning Search (BPPS) procedure in CHAIN simultaneously identifies selective constraints imposed on the foreground sequences, and pulls any sequences from the background that share the identified patterns in the query into the foreground, precisely defining a statistically supported family or subfamily if one exists [33].

\section{Additional material}

Additional file 1: Kinome annotations. Zip archive of hierarchical kinase classifications for each gene in the kinomes of each apicomplexan, plus P. marinus and T. pseudonana. Each file contains two tab-separated columns listing each gene's accession and kinase family assignment. Accessions are taken from the sources listed in Table 2.

Additional file 2: CMGC kinase family sizes. Number of copies of each conserved CMGC kinase family in each of the surveyed genomes.

Additional file 3: CDK-SCTTLRE subfamily FASTA alignment. Plaintext alignment of the kinase domains of the 14 sequences belonging to proposed CDK subfamily ("SCTTLRE"), in FASTA format.

Additional file 4: CDK-SCTTLRE subfamily CHAIN alignment versus the CDK family. Colorized sequence alignment and partition generated by the CHAIN program, comparing the apicomplexan-specific subfamily of CDKs to a diverse set of eukaryotic CDKs. CHAIN compares a given "query" set (here, members of the putative subfamily) to a larger "main" set (here, a diverse set of eukaryotic CDKs) and divides the main set into 3 partitions based on contrasting levels of residue conservation: a "foreground" set of sequences with residue motifs matching the query, a "background" which does not conserve the distinguishing motifs of the foreground, and an "intermediate" which contains sequences that may partially match both the foreground and background sequence motifs. The alignment summary generated by CHAIN displays only the aligned sequences in the query, but highlights the alignment columns according to the conservation patterns defining each partition. The alignment appears as three blocks, labeled "Intermediate", "Background" and "Foreground", corresponding to those partitions. Above each block is a histogram indicating residue conservation patterns unique to that sequence set; dots above each column indicate which columns form the distinguishing pattern. Thus, tall red bars above columns in the

"Foreground" block indicate residues that are strikingly conserved in the foreground, but not in the background. The rows below each "Background" and "Foreground" block indicate the conserved residue types and their conservation levels within those sequence sets, in units of $10 \%$.

Additional file 5: CDK-SCTTLRE subfamily CHAIN alignment versus the CDC2 subfamily. Colorized sequence alignment and partition generated by the CHAIN program, comparing the apicomplexan-specific subfamily of CDKs to eukaryotic CDC2 subfamily members. 
Additional file 6: CDPK subfamily FASTA alignment. Plain-text alignment of the 76 kinase domain sequences belonging to the proposed CDPK subfamily, in FASTA format.

Additional file 7: CDPK subfamily CHAIN alignment. Colorized sequence alignment and partition generated by the CHAIN program, comparing the lineage-specific subfamily of CDPKs to a large set of chromalveolate CDPKs.

Additional file 8: CpCDPK2 and MAPK structure alignment for PyMOL. PyMOL script to superimpose structures of CPCDPK2 and phosphorylated mammalian p38 $\alpha$, a MAP kinase. The structures are automatically downloaded from the WwPDB server and aligned within PyMOL. Constrastingly conserved CPCDPK2 residues identified by CHAIN, and the equivalents in $p 38 \alpha$, are highlighted as sticks. The reader is encouraged to explore nearby side chains and other features using the built-in capabilities of PyMOL

Additional file 9: Alignment of selected CDPK subfamily and MAPK sequences. Annotated alignment of CDPK subfamily representatives CpCDPK2 and PfCDPK5 with human MAPK sequences p38, JNK1 and ERK1. GUIDANCE [100] was used to align the sequence segments, calculate reliability scores, and generate the initial version of the figure, to which we added further annotations.

Additional file 10: CLK family FASTA alignment. Plain-text alignment of the kinase domains of 33 sequences belonging to a divergent clade of CLK, in FASTA format.

Additional file 11: CLK family CHAIN alignment. Colorized sequence alignment and partition generated by the CHAIN program, comparing the apicomplexan-specific subfamily of CLKs to a diverse set of eukaryotic CLKs.

Additional file 12: CLK family structure alignment for PyMOL PyMOL script to superimpose structures of PfLAMMER and human Clk2 and CIK3. Constrastingly conserved PfLAMMER residues identified by CHAIN, and the equivalents in the human CLKs, are highlighted as sticks.

\section{Acknowledgements}

We would like to thank Jessica C. Kissinger for valuable discussions related to this project and a critical review of a draft of this manuscript. We also thank the two anonymous reviewers for their detailed comments and advice on this manuscript.

We acknowledge the important contributions of the Structural Genomics Consortium in providing relevant crystal structures, many of which have been made public prior to the publication of an accompanying journal article. The Wellcome Trust Sanger Institute Pathogen Sequence Unit generously provided pre-publication access to genomic sequences. Funding for NK from the University of Georgia is acknowledged.

\section{Author details}

'Institute of Bioinformatics, University of Georgia, Athens, GA 30602, USA.

2Department of Biochemistry, University of Georgia, Athens, GA 30602, USA.

\section{Authors' contributions}

NK designed and conceived the project. ET performed the bioinformatics analyses. ET, AM and NK examined sequences and structural features and wrote the manuscript. All authors read and approved the final manuscript.

Received: 14 June 2011 Accepted: 2 November 2011

Published: 2 November 2011

\section{References}

1. Roos DS: Genetics. Themes and variations in apicomplexan parasite biology. Science 2005, 309(5731):72-3.

2. Renslo AR, McKerrow JH: Drug discovery and development for neglected parasitic diseases. Nature chemical biology 2006, 2(12):701-10

3. Sibley LD: Intracellular parasite invasion strategies. Science 2004, 304(5668):248-53.
4. Hammarton T: The cell cycle of parasitic protozoa: potential for chemotherapeutic exploitation. Progress in Cell Cycle Research 2003, 5:91-101,

5. Doerig C, Abdi A, Bland N, Eschenlauer S, Dorin-Semblat D, Fennell C, Halbert J, Holland Z, Nivez MP, Semblat JP, Sicard A, Reininger L: Malaria: targeting parasite and host cell kinomes. Biochimica et biophysica acta 2010, 1804(3):604-12.

6. Hall N, Karras M, Raine JD, Carlton JM, Kooij TWa, Berriman M, Florens L, Janssen CS, Pain A, Christophides GK, James K, Rutherford K, Harris B, Harris D, Churcher C, Quail Ma, Ormond D, Doggett J, Trueman HE, Mendoza J, Bidwell SL, Rajandream MA, Carucci DJ, Yates JR, Kafatos FC, Janse CJ, Barrell B, Turner CMR, Waters AP, Sinden RE: A comprehensive survey of the Plasmodium life cycle by genomic, transcriptomic, and proteomic analyses. Science 2005, 307(5706):82-6.

7. Gardner MJ, Hall N, Fung E, White O, Berriman M, Hyman RW, Carlton JM, Pain A, Nelson KE, Bowman S, Paulsen IT, James K, Eisen Ja, Rutherford K, Salzberg SL, Craig A, Kyes S, Chan MS, Nene V, Shallom SJ, Suh B, Peterson J, Angiuoli S, Pertea M, Allen J, Selengut J, Haft D, Mather MW, Vaidya AB, Martin DMa, Fairlamb AH, Fraunholz MJ, Roos DS, Ralph Sa, McFadden Gl, Cummings LM, Subramanian GM, Mungall C, Venter JC, Carucci DJ, Hoffman SL, Newbold C, Davis RW, Fraser CM, Barrell B: Genome sequence of the human malaria parasite Plasmodium falciparum. Nature 2002, 419(6906):498-511.

8. Pain $a$, Böhme $U$, Berry aE, Mungall $K$, Finn RD, Jackson aP, Mourier $T$, Mistry J, Pasini EM, Aslett Ma, Balasubrammaniam S, Borgwardt K, Brooks K, Carret C, Carver TJ, Cherevach I, Chillingworth T, Clark TG, Galinski MR, Hall N, Harper D, Harris D, Hauser H, Ivens A, Janssen CS, Keane T, Larke N, Lapp S, Marti M, Moule S, Meyer IM, Ormond D, Peters N, Sanders M, Sanders S, Sargeant TJ, Simmonds M, Smith F, Squares R, Thurston S, Tivey aR, Walker D, White B, Zuiderwijk E, Churcher C, Quail Ma, Cowman aF, Turner CMR, Rajandream Ma, Kocken CHM, Thomas aW, Newbold Cl, Barrell BG, Berriman M: The genome of the simian and human malaria parasite Plasmodium knowlesi. Nature 2008, 455(7214):799-803.

9. Carlton JM, Adams JH, Silva JC, Bidwell SL, Lorenzi H, Caler E, Crabtree J, Angiuoli SV, Merino EF, Amedeo P, Cheng Q, Coulson RMR, Crabb BS, Del Portillo Ha, Essien K, Feldblyum TV, Fernandez-Becerra C, Gilson PR, Gueye AH, Guo X, Kang'a S, Kooij TWa, Korsinczky M, Meyer EVS, Nene V, Paulsen I, White O, Ralph Sa, Ren Q, Sargeant TJ, Salzberg SL, Stoeckert CJ, Sullivan Sa, Yamamoto MM, Hoffman SL, Wortman JR, Gardner MJ, Galinski MR, Barnwell JW, Fraser-Liggett CM: Comparative genomics of the neglected human malaria parasite Plasmodium vivax. Nature 2008, 455(7214):757-63.

10. Carlton JM, Angiuoli SV, Suh BB, Kooij TW, Pertea M, Silva JC, Ermolaeva MD, Allen JE, Selengut JD, Koo HL, Peterson JD, Pop M, Kosack DS, Shumway MF, Bidwell SL, Shallom SJ, van Aken SE, Riedmuller SB, Feldblyum TV, Cho JK, Quackenbush J, Sedegah M, Shoaibi A, Cummings LM, Florens L, Yates JR, Raine JD, Sinden RE, Harris $M a$, Cunningham Da, Preiser $P R$, Bergman $L W$, Vaidya $A B$, van $L$ in $L H$, Janse CJ, Waters AP, Smith HO, White OR, Salzberg SL, Venter JC, Fraser CM, Hoffman SL, Gardner MJ, Carucci DJ: Genome sequence and comparative analysis of the model rodent malaria parasite Plasmodium yoelii yoelii. Nature 2002, 419(6906):512-9.

11. Brayton Ka, Lau AOT, Herndon DR, Hannick L, Kappmeyer LS, Berens SJ, Bidwell SL, Brown WC, Crabtree J, Fadrosh D, Feldblum T, Forberger HA, Haas BJ, Howell JM, Khouri H, Koo H, Mann DJ, Norimine J, Paulsen IT, Radune D, Ren Q, Smith RK, Suarez CE, White O, Wortman JR, Knowles DP, McElwain TF, Nene VM: Genome sequence of Babesia bovis and comparative analysis of apicomplexan hemoprotozoa. PLOS pathogens 2007, 3(10):1401-13.

12. Pain A, Renauld H, Berriman M, Murphy L, Yeats Ca, Weir W, Kerhornou A, Aslett M, Bishop R, Bouchier C, Cochet M, Coulson RMR, Cronin A, de Villiers EP, Fraser A, Fosker N, Gardner M, Goble A, Griffths-Jones S, Harris DE, Katzer F, Larke N, Lord A, Maser P, McKellar S, Mooney P, Morton F, Nene V, O'Neil S, Price C, Quail Ma, Rabbinowitsch E, Rawlings ND, Rutter S, Saunders D, Seeger K, Shah T, Squares R, Squares S, Tivey A, Walker AR, Woodward J, Dobbelaere DaE, Langsley G, Rajandream MA, McKeever D, Shiels B, Tait A, Barrell B, Hall N: Genome of the host-cell transforming parasite Theileria annulata compared with $T$. parva. Science 2005, 309(5731):131-3. 
13. Gardner MJ, Bishop R, Shah T, de Villiers EP, Carlton JM, Hall N, Ren Q, Paulsen IT, Pain A, Berriman M, Wilson RJM, Sato S, Ralph Sa, Mann DJ, Xiong Z, Shallom SJ, Weidman J, Jiang L, Lynn J, Weaver B, Shoaibi A, Domingo AR, Wasawo D, Crabtree J, Wortman JR, Haas B, Angiuoli SV, Creasy TH, Lu C, Suh B, Silva JC, Utterback TR, Feldblyum TV, Pertea M, Allen J, Nierman WC, Taracha ELN, Salzberg SL, White OR, Fitzhugh Ha, Morzaria S, Venter JC, Fraser CM, Nene V: Genome sequence of Theileria parva, a bovine pathogen that transforms lymphocytes. Science 2005, 309(5731):134-7.

14. Heiges M, Wang H, Robinson E, Aurrecoechea C, Gao X, Kaluskar N, Rhodes P, Wang S, He CZ, Su Y, Miller J, Kraemer E, Kissinger JC: CryptoDB: a Cryptosporidium bioinformatics resource update. Nucleic acids research 2006, , 34 Database: D419-22.

15. Xu P, Widmer G, Wang Y, Ozaki LS, Alves JM, Serrano MG, Puiu D, Manque P, Akiyoshi D, Mackey AJ, Pearson WR, Dear PH, Bankier AT, Peterson DL, Abrahamsen MS, Kapur V, Tzipori S, Buck GA: The genome of Cryptosporidium hominis. Nature 2004, 431(7012):1107-12.

16. Abrahamsen MS, Templeton TJ, Enomoto S, Abrahante JE, Zhu G, Lancto Ca, Deng M, Liu C, Widmer G, Tzipori S, Buck Ga, Xu P, Bankier AT, Dear PH, Konfortov Ba, Spriggs HF, lyer L, Anantharaman V, Aravind L, Kapur V: Complete genome sequence of the apicomplexan, Cryptosporidium parvum. Science 2004, 304(5669):441-5.

17. Bontell IL, Hall N, Ashelford KE, Dubey JP, Boyle JP, Lindh J, Smith JE: Whole genome sequencing of a natural recombinant Toxoplasma gondii strain reveals chromosome sorting and local allelic variants. Genome biology 2009, 10(5):R53.

18. Dorin D, Semblat JP, Poullet P, Alano P, Goldring JPD, Whittle C, Patterson S, Chakrabarti D, Doerig C: PfPK7, an atypical MEK-related protein kinase, reflects the absence of classical three-component MAPK pathways in the human malaria parasite Plasmodium falciparum. Molecular microbiology 2005, 55:184-96.

19. Lourido S, Shuman J, Zhang C, Shokat KM, Hui R, Sibley LD: Calciumdependent protein kinase 1 is an essential regulator of exocytosis in Toxoplasma. Nature 2010, 465(7296):359-62.

20. Tewari R, Straschil U, Bateman A, Böhme U, Cherevach I, Gong P, Pain A, Billker $O$ : The systematic functional analysis of Plasmodium protein kinases identifies essential regulators of mosquito transmission. Cell host \& microbe 2010, 8(4):377-87.

21. Ward $P$, Equinet $L$, Packer J, Doerig C: Protein kinases of the human malaria parasite Plasmodium falciparum: the kinome of a divergent eukaryote. BMC Genomics 2004, 5:79.

22. Sargeant TJ, Marti M, Caler E, Carlton JM, Simpson K, Speed TP, Cowman AF: Lineage-specific expansion of proteins exported to erythrocytes in malaria parasites. Genome biology 2006, 7(2):R12.

23. Schneider AG, Mercereau-Puijalon O: A new Apicomplexa-specific protein kinase family: multiple members in Plasmodium falciparum, all with an export signature. BMC Genomics 2005, 6:30.

24. Peixoto L, Chen F, Harb OS, Davis PH, Beiting DP, Brownback CS, Ouloguem D, Roos DS: Integrative genomic approaches highlight a family of parasite-specific kinases that regulate host responses. Cell host \& microbe 2010, 8(2):208-18.

25. Dorin-Semblat D, Sicard A, Doerig C, Ranford-Cartwright L, Doerig C Disruption of the PfPK7 gene impairs schizogony and sporogony in the human malaria parasite Plasmodium falciparum. Eukaryotic cell 2008, 7(2):279-85.

26. Merckx A, Echalier A, Langford K, Sicard A, Langsley G, Joore J, Doerig C, Noble M, Endicott J: Structures of P. falciparum protein kinase 7 identify an activation motif and leads for inhibitor design. Structure 2008, 16(2):228-38.

27. Hanks SK, Hunter T: The eukaryotic protein kinase superfamily: kinase (catalytic) domain structure and classification. FASEB 1995, 9:576-596.

28. Manning G, Whyte DB, Martinez R, Hunter T, Sudarsanam S: The protein kinase complement of the human genome. Science 2002, 298(5600):1912-34.

29. Nagamune K, Sibley LD: Comparative genomic and phylogenetic analyses of calcium ATPases and calcium-regulated proteins in the apicomplexa. Molecular biology and evolution 2006, 23(8):1613-27.

30. Wernimont AK, Artz JD, Finerty P, Lin YH, Amani M, Allali-Hassani A, Senisterra G, Vedadi M, Tempel W, Mackenzie F, Chau I, Lourido S, Sibley LD, Hui R: Structures of apicomplexan calcium-dependent protein kinases reveal mechanism of activation by calcium. Nature structural \& molecular biology 2010, 17(5):596-601.

31. Billker $\mathrm{O}$, Lourido S, Sibley L: Calcium-dependent signaling and kinases in apicomplexan parasites. Cell host \& microbe 2009, 5(6):612-622.

32. Artz J, Wernimont A, Allali-Hassani A, Zhao Y, Amani M, Lin YH, Senisterra G, Wasney G, Fedorov O, King O, Roos A, Lunin V, Qiu W, Finerty P, Hutchinson A, Chau I, von Delft F, MacKenzie F, Lew J, Kozieradzki I, Vedadi M, Schapira M, Zhang C, Shokat K, Heightman T, Hui R: The Cryptosporidium parvum Kinome. BMC Genomics 2011, 12:478.

33. Neuwald AF: The CHAIN program: forging evolutionary links to underlying mechanisms. Trends in biochemical sciences 2007, 32(11):487-93.

34. Berman HM, Westbrook J, Feng Z, Gilliland G, Bhat TN, Weissig H, Shindyalov IN, Bourne PE: The Protein Data Bank. Nucleic acids research 2000, 28:235-42.

35. Keeling PJ, Burger G, Durnford DG, Lang BF, Lee RW, Pearlman RE, Roger AJ, Gray MW: The tree of eukaryotes. Trends in ecology \& evolution 2005, 20(12):670-6.

36. Adl SM, Simpson AGB, Farmer MA, Andersen RA, Anderson OR, Barta JR, Bowser SS, Brugerolle G, Fensome RA, Fredericq S, James TY, Karpov S, Kugrens P, Krug J, Lane CE, Lewis LA, Lodge J, Lynn DH, Mann DG, McCourt RM, Mendoza L, Moestrup O, Mozley-Standridge SE, Nerad TA, Shearer CA, Smirnov AV, Spiegel FW, Taylor MFJR: The new higher level classification of eukaryotes with emphasis on the taxonomy of protists. The Journal of eukaryotic microbiology 2005, 52(5):399-451.

37. Joseph SJ, Fernández-Robledo JA, Gardner MJ, El-Sayed NM, Kuo CH, Schott EJ, Wang H, Kissinger JC, Vasta GR: The Alveolate Perkinsus marinus: biological insights from EST gene discovery. BMC Genomics 2010, 11:228.

38. Bemm F, Schwarz R, Förster F, Schultz J: A kinome of 2600 in the ciliate Paramecium tetraurelia. FEBS letters 2009, 583(22):3589-92.

39. Miranda-Saavedra D, Stark MJR, Packer JC, Vivares CP, Doerig C, Barton GJ: The complement of protein kinases of the microsporidium Encephalitozoon cuniculi in relation to those of Saccharomyces cerevisiae and Schizosaccharomyces pombe. BMC Genomics 2007, 8:309.

40. Lawrence JG: Common themes in the genome strategies of pathogens. Current opinion in genetics \& development 2005, 15(6):584-8.

41. Templeton TJ, lyer LM, Anantharaman V, Enomoto S, Abrahante JE, Subramanian GM, Hoffman SL, Abrahamsen MS, Aravind L: Comparative analysis of apicomplexa and genomic diversity in eukaryotes. Genome research 2004, 14(9):1686-95.

42. Kuo CH, Kissinger JC: Consistent and contrasting properties of lineagespecific genes in the apicomplexan parasites Plasmodium and Theileria. BMC Evolutionary Biology 2008, 8:108.

43. Martin DMa, Miranda-Saavedra D, Barton GJ: Kinomer v. 1.0: a database of systematically classified eukaryotic protein kinases. Nucleic acids research 2009, , 37 Database: D244-50.

44. Striepen B, Jordan CN, Reiff S, van Dooren GG: Building the perfect parasite: cell division in apicomplexa. PLoS pathogens 2007, 3(6):e78.

45. Colwill K, Feng LL, Yeakley JM, Gish GD, Cáceres JF, Pawson T, Fu XD: SRPK1 and Clk/Sty protein kinases show distinct substrate specificities for serine/arginine-rich splicing factors. The Journal of biological chemistry 1996, 271(40):24569-75.

46. Kojima T, Zama T, Wada K, Onogi H, Hagiwara M: Cloning of human PRP4 reveals interaction with Clk1. The Journal of biological chemistry 2001, 276(34):32247-56.

47. Bullock AN, Das S, Debreczeni JE, Rellos P, Fedorov O, Niesen FH, Guo K, Papagrigoriou E, Amos AL, Cho S, Turk BE, Ghosh G, Knapp S: Kinase domain insertions define distinct roles of CLK kinases in SR protein phosphorylation. Structure (London, England: 1993) 2009, 17(3):352-62.

48. Kannan N, Neuwald AF: Evolutionary constraints associated with functional specificity of the CMGC protein kinases MAPK, CDK, GSK, SRPK, DYRK, and CK2alpha. Protein science: a publication of the Protein Society 2004, 13(8):2059-77.

49. Dixit A, Singh PK, Sharma GP, Malhotra P, Sharma P: PfSRPK1, a novel splicing-related kinase from Plasmodium falciparum. The Journal of biological chemistry 2010, 285(49):38315-23.

50. Yun B, Farkas R, Lee K, Rabinow L: The Doa locus encodes a member of a new protein kinase family and is essential for eye and embryonic development in Drosophila melanogaster. Genes \& Development 1994, 8(10):1160-1173 
51. Agarwal S, Kern S, Halbert J, Przyborski JM, Baumeister S, Dandekar T, Doerig C, Pradel G: Two nucleus-localized CDK-like kinases with crucial roles for malaria parasite erythrocytic replication are involved in phosphorylation of splicing factor. Journal of cellular biochemistry 2011, 112(5):1295-310

52. Fluhr R: Regulation of Splicing by Protein Phosphorylation. In Nuclear premRNA Processing in Plants, Volume 326 of Current Topics in Microbiology and Immunology. Edited by: Reddy ASN, Golovkin M. Berlin, Heidelberg: Springer Berlin Heidelberg; 2008:119-138.

53. Chen F, Mackey AJ, Stoeckert CJ, Roos DS: OrthoMCL-DB: querying a comprehensive multi-species collection of ortholog groups. Nucleic acids research 2006, , 34 Database: D363-8.

54. Wernimont AK, Amani M, Qiu W, Pizarro JC, Artz JD, Lin YH, Lew J, Hutchinson A, Hui R: Structures of parasitic CDPK domains point to a common mechanism of activation. Proteins 2010, 1-18.

55. Ojo KK, Larson ET, Keyloun KR, Castaneda L, Derocher AE, Inampudi KK, Kim JE, Arakaki TL, Murphy RC, Zhang L, Napuli AJ, Maly DJ, Verlinde CLMJ, Buckner FS, Parsons M, Hol WGJ, Merritt EA, Van Voorhis WC: Toxoplasma gondii calcium-dependent protein kinase 1 is a target for selective kinase inhibitors. Nature structural \& molecular biology 2010, 17(5):602-7.

56. Nishida E, Gotoh Y: The MAP kinase cascade is essential for diverse signal transduction pathways. Trends in biochemical sciences 1993, 18(4):128-31.

57. Srinivasan N, Krupa a: A genomic perspective of protein kinases in Plasmodium falciparum. Proteins 2005, 58:180-9.

58. Eisen JA, Coyne RS, Wu M, Wu D, Thiagarajan M, Wortman JR, Badger JH, Ren Q, Amedeo P, Jones KM, Tallon LJ, Delcher AL, Salzberg SL, Silva JC, Haas BJ, Majoros WH, Farzad M, Carlton JM, Smith RK, Garg J, Pearlman RE, Karrer KM, Sun L, Manning G, Elde NC, Turkewitz AP, Asai DJ, Wilkes DE, Wang Y, Cai H, Collins K, Stewart BA, Lee SR, Wilamowska K, Weinberg Z, Ruzzo WL, Wloga D, Gaertig J, Frankel J, Tsao CC, Gorovsky MA, Keeling PJ, Waller RF, Patron NJ, Cherry JM, Stover NA, Krieger CJ, del Toro C, Ryder HF, Williamson SC, Barbeau RA, Hamilton EP, Orias E: Macronuclear genome sequence of the ciliate Tetrahymena thermophila, a model eukaryote. PLoS biology 2006, 4(9):e286.

59. Doerig C, Billker O, Pratt D, Endicott J: Protein kinases as targets for antimalarial intervention: Kinomics, structure-based design, transmissionblockade, and targeting host cell enzymes. Biochimica et biophysica acta 2005, 1754(1-2):132-50

60. Dorin D, Le Roch K, Sallicandro P, Alano P, Parzy D, Poullet P, Meijer L, Doerig C: Pfnek-1, a NIMA-related kinase from the human malaria parasite Plasmodium falciparum. European Journal of Biochemistry 2001, 268(9):2600-2608.

61. Nunes MC, Goldring JPD, Doerig C, Scherf A: A novel protein kinase family in Plasmodium falciparum is differentially transcribed and secreted to various cellular compartments of the host cell. Molecular microbiology 2007, 63(2):391-403.

62. Nunes MC, Okada M, Scheidig-Benatar C, Cooke BM, Scherf A: Plasmodium falciparum FIKK Kinase Members Target Distinct Components of the Erythrocyte Membrane. PloS one 2010, 5(7):e11747.

63. Shaw MK: Cell invasion by Theileria sporozoites. Trends in parasitology 2003, 19:2-6.

64. Bradley PJ, Ward C, Cheng SJ, Alexander DL, Coller S, Coombs GH, Dunn JD, Ferguson DJ, Sanderson SJ, Wastling JM, Boothroyd JC: Proteomic analysis of rhoptry organelles reveals many novel constituents for host-parasite interactions in Toxoplasma gondii. The Journal of biological chemistry 2005, 280(40):34245-58.

65. Boothroyd JC, Dubremetz JF: Kiss and spit: the dual roles of Toxoplasma rhoptries. Nature reviews Microbiology 2008, 6:79-88.

66. El Hajj H, Lebrun M, Arold ST, Vial H, Labesse G, Dubremetz JF: ROP18 is a rhoptry kinase controlling the intracellular proliferation of Toxoplasma gondii. PLoS pathogens 2007, 3(2):e14

67. Qiu W, Wernimont AK, Tang K, Taylor S, Lunin V, Schapira M, Fentress S, Hui R, Sibley LD: Novel structural and regulatory features of rhoptry secretory kinases in Toxoplasma gondii. The EMBO journal 2009, 28(7):969-79.

68. Sibley LD, Ajioka JW: Population structure of Toxoplasma gondii: clonal expansion driven by infrequent recombination and selective sweeps. Annual review of microbiology 2008, 62:329-51.

69. Delano W: The PyMOL Molecular Graphics System, Version 1.4. 2011.

70. Cock PJA, Antao T, Chang JT, Chapman BA, Cox CJ, Dalke A, Friedberg I, Hamelryck T, Kauff F, Wilczynski B, de Hoon MJL: Biopython: freely available Python tools for computational molecular biology and bioinformatics. Bioinformatics (Oxford, England) 2009, 25(11):1422-3.

71. Morgan DO: Cyclin-dependent kinases: engines, clocks, and microprocessors. Annual review of cell and developmental biology 1997, 13:261-91.

72. Brown NR, Noble ME, Endicott JA, Johnson LN: The structural basis for specificity of substrate and recruitment peptides for cyclin-dependent kinases. Nature cell biology 1999, 1(7):438-43.

73. Doerig C, Endicott J, Chakrabarti D: Cyclin-dependent kinase homologues of Plasmodium falciparum. International journal for parasitology 2002, 32(13):1575-85.

74. Doerig C: Protein kinases regulating Plasmodium proliferation and development. In Molecular approaches to malaria. Edited by: Sherman IW. Washington, D.C.: ASM Press; 2005:290-310.

75. Harper JF, Harmon A: Plants, symbiosis and parasites: a calcium signalling connection. Nature reviews Molecular cell biology 2005, 6(7):555-66.

76. Dvorin JD, Martyn DC, Patel SD, Grimley JS, Collins CR, Hopp CS, Bright aT, Westenberger S, Winzeler E, Blackman MJ, Baker Da, Wandless TJ, Duraisingh MT: A plant-like kinase in Plasmodium falciparum regulates parasite egress from erythrocytes. Science 2010, 328(5980):910-2.

77. Ahn YM, Clare M, Ensinger CL, Hood MM, Lord JW, Lu WP, Miller DF, Patt WC, Smith BD, Vogeti L, Kaufman MD, Petillo Pa, Wise SC, Abendroth J, Chun L, Clark R, Feese M, Kim H, Stewart L, Flynn DL: Switch control pocket inhibitors of p38-MAP kinase. Durable type II inhibitors that do not require binding into the canonical ATP hinge region. Bioorganic \& medicinal chemistry letters 2010, 20(19):5793-8.

78. Bellon S, Fitzgibbon M, Fox T, Hsiao H: The structure of phosphorylated P38 is monomeric and reveals a conserved activation-loop conformation. Structure 1999, 1057-1065.

79. Li JL, Targett GA, Baker DA: Primary structure and sexual stage-specific expression of a LAMMER protein kinase of Plasmodium falciparum. International Journal for Parasitology 2001, 31(4):387-392.

80. Golovkin M, Reddy aS: An SC35-like protein and a novel serine/argininerich protein interact with Arabidopsis U1-70K protein. The Journal of biological chemistry 1999, 274(51):36428-38.

81. Iriko H, Jin L, Kaneko O, Takeo S, Han ET, Tachibana M, Otsuki H, Torii M, Tsuboi T: A small-scale systematic analysis of alternative splicing in Plasmodium falciparum. Parasitology international 2009, 58(2):196-9.

82. Velazquez-Dones A, Hagopian JC, Ma CT, Zhong XY, Zhou H, Ghosh G, Fu XD, Adams Ja: Mass spectrometric and kinetic analysis of ASF/SF2 phosphorylation by SRPK1 and Clk/Sty. The Journal of biological chemistry 2005, 280(50):41761-8.

83. Ngo JCK, Chakrabarti S, Ding JH, Velazquez-Dones A, Nolen B, Aubol BE, Adams Ja, Fu XD, Ghosh G: Interplay between SRPK and Clk/Sty kinases in phosphorylation of the splicing factor ASF/SF2 is regulated by a docking motif in ASF/SF2. Molecular cell 2005, 20:77-89.

84. Emsley P, Cowtan K: Coot: model-building tools for molecular graphics. Acta crystallographica. Section D, Biological crystallography 2004, 60(Pt 12 Pt 1):2126-32.

85. Rodgers JT, Haas W, Gygi SP, Puigserver P: Cdc2-like kinase 2 is an insulinregulated suppressor of hepatic gluconeogenesis. Cell metabolism 2010, 11:23-34.

86. Nikolakaki E, Du C, Lai J, Giannakouros T, Cantley L, Rabinow L: Phosphorylation by LAMMER protein kinases: determination of a consensus site, identification of in vitro substrates, and implications for substrate preferences. Biochemistry 2002, 41(6):2055-66.

87. Gileadi O, Knapp S, Lee WH, Marsden BD, Müller S, Niesen FH, Kavanagh KL, Ball $L$, von Delft F, Doyle Da, Oppermann UCT, Sundström M: The scientific impact of the Structural Genomics Consortium: a protein family and ligand-centered approach to medically-relevant human proteins. Journal of structural and functional genomics 2007, 8(2-3):107-19.

88. Aurrecoechea C, Brestelli J, Brunk BP, Fischer S, Gajria B, Gao X, Gingle A, Grant G, Harb OS, Heiges M, Innamorato F, lodice J, Kissinger JC, Kraemer ET, Li W, Miller Ja, Nayak V, Pennington C, Pinney DF, Roos DS, Ross C, Srinivasamoorthy G, Stoeckert CJ, Thibodeau R, Treatman C, Wang H: EuPathDB: a portal to eukaryotic pathogen databases. Nucleic acids research 2010, , 38 Database: D415-9.

89. Kannan N, Taylor SS, Zhai Y, Venter JC, Manning G: Structural and functional diversity of the microbial kinome. PLoS biology 2007, 5(3):e17. 
90. Neuwald AF: Rapid detection, classification and accurate alignment of up to a million or more related protein sequences. Bioinformatics 2009, 25(15):1869-1875.

91. Stamatakis A: RAxML-VI-HPC: maximum likelihood-based phylogenetic analyses with thousands of taxa and mixed models. Bioinformatics 2006 22(21):2688-90.

92. Kuo $\mathrm{CH}$, Wares JP, Kissinger JC: The Apicomplexan whole-genome phylogeny: an analysis of incongruence among gene trees. Molecular biology and evolution 2008, 25(12):2689-98.

93. Pick C, Ebersberger I, Spielmann T, Bruchhaus I, Burmester T: Phylogenomic analyses of malaria parasites and evolution of their exported proteins. BMC evolutionary biology 2011, 11:167.

94. Xiao L, Sulaiman IM, Ryan UM, Zhou L, Atwill ER, Tischler ML, Zhang X, Fayer R, Lal Aa: Host adaptation and host-parasite co-evolution in Cryptosporidium: implications for taxonomy and public health. International journal for parasitology 2002, 32(14):1773-85.

95. Crooks GE, Hon G, Chandonia Jm, Brenner SE: WebLogo: a sequence logo generator. Genome research 2004, 14(6):1188-90.

96. Aurrecoechea C, Brestelli J, Brunk BP, Dommer J, Fischer S, Gajria B, Gao X, Gingle A, Grant G, Harb OS, Heiges M, Innamorato F, lodice J, Kissinger JC, Kraemer E, Li W, Miller JA, Nayak V, Pennington C, Pinney DF, Roos DS, Ross C, Stoeckert CJ, Treatman C, Wang H: PlasmoDB: a functional genomic database for malaria parasites. Nucleic acids research 2009, , 37 Database: D539-43.

97. Gajria B, Bahl A, Brestelli J, Dommer J, Fischer S, Gao X, Heiges M, lodice J, Kissinger JC, Mackey AJ, Pinney DF, Roos DS, Stoeckert CJ, Wang H, Brunk BP: ToxoDB: an integrated Toxoplasma gondii database resource. Nucleic acids research 2008, , 36 Database: D553-6.

98. Armbrust EV, Berges Ja, Bowler C, Green BR, Martinez D, Putnam NH, Zhou S, Allen AE, Apt KE, Bechner M, Brzezinski Ma, Chaal BK, Chiovitti A, Davis AK, Demarest MS, Detter JC, Glavina T, Goodstein D, Hadi MZ, Hellsten U, Hildebrand M, Jenkins BD, Jurka J, Kapitonov W, Kröger N, Lau WWY, Lane TW, Larimer FW, Lippmeier JC, Lucas S, Medina M, Montsant A, Obornik M, Parker MS, Palenik B, Pazour GJ, Richardson PM, Rynearson Ta, Saito Ma, Schwartz DC, Thamatrakoln K, Valentin K, Vardi A, Wilkerson FP, Rokhsar DS: The genome of the diatom Thalassiosira pseudonana: ecology, evolution, and metabolism. Science 2004, 306(5693):79-86.

99. Bowler C, Allen AE, Badger JH, Grimwood J, Jabbari K, Kuo A, Maheswari U, Martens C, Maumus F, Otillar RP, Rayko E, Salamov A, Vandepoele K, Beszteri B, Gruber A, Heijde M, Katinka M, Mock T, Valentin K, Verret F, Berges Ja, Brownlee C, Cadoret JP, Chiovitti A, Choi CJ, Coesel S, De Martino A, Detter JC, Durkin C, Falciatore A, Fournet J, Haruta M, Huysman MJJ, Jenkins BD, Jiroutova K, Jorgensen RE, Joubert Y, Kaplan A,

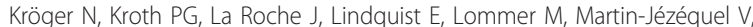
Lopez PJ, Lucas S, Mangogna M, McGinnis K, Medlin LK, Montsant A, Oudot-Le Secq MP, Napoli C, Obornik M, Parker MS, Petit JL, Porcel BM, Poulsen N, Robison M, Rychlewski L, Rynearson Ta, Schmutz J, Shapiro H, Siaut M, Stanley M, Sussman MR, Taylor AR, Vardi A, von Dassow P, Vyverman W, Willis A, Wyrwicz LS, Rokhsar DS, Weissenbach J, Armbrust EV, Green BR, Van de Peer Y, Grigoriev IV: The Phaeodactylum genome reveals the evolutionary history of diatom genomes. Nature 2008 456(7219):239-44.

100. Penn O, Privman E, Ashkenazy H, Landan G, Graur D, Pupko T: GUIDANCE: a web server for assessing alignment confidence scores. Nucleic acids research 2010, , 38 Web Server: W23-8.

doi:10.1186/1471-2148-11-321

Cite this article as: Talevich et al: Structural and evolutionary divergence of eukaryotic protein kinases in Apicomplexa. BMC Evolutionary Biology 2011 11:321.

\section{Submit your next manuscript to BioMed Central and take full advantage of:}

- Convenient online submission

- Thorough peer review

- No space constraints or color figure charges

- Immediate publication on acceptance

- Inclusion in PubMed, CAS, Scopus and Google Scholar

- Research which is freely available for redistribution

Submit your manuscript at www.biomedcentral.com/submit
C) Biomed Central 